\title{
EL ESTATUTO DE LOS PARLAMENTARIOS EN UN CONTEXTO MULTINIVEL: LAS RELACIONES ENTRE PARLAMENTARIOS, GRUPOS Y PARTIDOS
}

CRISTINA PAUNER CHULVI 
SUMARIO

1. INTRODUCCIÓN: LA POSICIÓN CONSTITUCIONAL DEL PARLAMENTARIO ANTE EL DESGASTE DE LA TEORÍA DEL MANDATO REPRESENTATIVO. 2. LAS RELACIONES ENTRE LOS GRUPOS PARLAMENTARIOS Y LOS PARTIDOS POLÍTICOS. MARCO NORMATIVO. A) La regulación estatal y autonómica de las relaciones entre grupo y partido: Constitución, Estatutos de Autonomía y Reglamentos parlamentarios. B) La normativa interna de los partidos y grupos: los Estatutos de partido y los Reglamentos internos del grupo. a) El ideario político del partido y su recepción por el grupo. b) La simbiosis entre las direcciones del partido y del grupo. 3. LAS RELACIONES ENTRE LOS GRUPOS PARLAMENTARIOS Y SUS MIEMBROS. A) La posición del parlamentario en el grupo. B) La disciplina de voto. 4. PARTIDOS, GRUPOS Y DIPUTADOS EN EL PARLAMENTO EUROPEO: LA PLURALIDAD DE MANDATOS. 5. REFLEXIONES FINALES. 


\title{
EL ESTATUTO DE LOS PARLAMENTARIOS EN UN CONTEXTO MULTINIVEL: LAS RELACIONES ENTRE PARLAMENTARIOS, GRUPOS Y PARTIDOS*
}

\author{
POR \\ CRISTINA PAUNER CHULVI \\ Profesora Titular de Derecho Constitucional \\ Universitat Jaume I de Castellón \\ pauner@dpu.uji.es
}

1. INTRODUCCIÓN: LA POSICIÓN CONSTITUCIONAL DEL PARLAMENTARIO ANTE EL DESGASTE DE LA TEORÍA DEL MANDATO REPRESENTATIVO

El Parlamento actual es un Parlamento de grupos quienes, a su vez, constituyen el trasunto en las Cámaras de los partidos políticos difuminándose de esta manera la figura del parlamentario. Esta realidad es la que ha alumbrado expresiones como Estado o democracia de partidos, Parlamento grupocrático,... Con todas ellas se pone el acento en el papel clave que han adquirido estas en-

* El presente trabajo de investigación se ha elaborado en el marco del proyecto del Plan Nacional de I+D+i 2010-2012 del Ministerio de Ciencia e Innovación (referencia CSO200914381-C03-03). 
tidades para la conformación de los órganos del Estado y el desarrollo de la democracia actual.

En el origen de las transformaciones que ha sufrido la teoría política evolucionando desde los postulados de la democracia liberal representativa hasta la democracia de partidos se encuentran, efectivamente, los grupos parlamentarios y los partidos políticos ${ }^{1}$. Así, en el Parlamento liberal la representación se basaba en la expresión de la voluntad popular a través de sus representantes, los parlamentarios, que se conducían como voluntades libres no sometidos a mandato imperativo mientras que, en la actualidad, el Estado de partidos ha generado que el Parlamento funcione sobre la base de la representación colectiva a través de los partidos políticos: los representantes actúan como portavoces de su propio partido mediante el sometimiento a la disciplina del grupo.

No son pocos los autores que han denunciado por irreal esa visión del pasado caracterizada por la autonomía del parlamentario individual no mediatizado por la presencia de los partidos políticos; por la iniciativa y dirección parlamentaria del procedimiento legislativo; por el carácter ilimitado y sin barreras de los procedimientos de control y exigencia de responsabilidad - lo que García Morillo ha denominado el mito de la «imprevisibilidad del comportamiento parlamentario ${ }^{2}-\mathrm{y}$ han subrayado que, de una forma u otra, los partidos políticos y su emanación parlamentaria, los grupos parlamentarios, siempre han sido un factor relevante en la vida de las Cámaras ${ }^{3}$.

Las relaciones entre estos tres sujetos - partidos políticos, grupos parlamentarios y sus miembros- se producen en niveles diversos y con diferentes consecuencias jurídicas o políticas sobre el estatuto de los representantes individuales. El ejercicio de estas relaciones será siempre un medio instrumental para que el Parlamento o sus miembros cumplan efectivamente sus funciones constitucionales o estatutarias pero, como veremos, estos vínculos tienen una poderosa incidencia sobre las disposiciones que regulan los procedimientos parlamentarios, sustituyéndolas en la práctica y desplegando, incluso, una eficacia derogatoria de las mismas.

1 DUVERGER, Maurice, Los partidos políticos, FCE, México, 2002.

2 GARCÍA MORILLO, Joaquín, «El Parlamento ante las nuevas realidades», en El Parlamento y sus transformaciones actuales, Tecnos, Madrid, 1990, p. 144.

3 Entre otros, SÁIZ ARNÁIZ, Alejandro, Los grupos parlamentarios, Congreso de los Diputados, Madrid, 1989, p. 229; TORRES DEL MORAL, Antonio, «El Estado español de partidos», Revista del Centro de Estudios Constitucionales, núm. 8, 1991, p. 132 y LÓPEZ GUERRA, Luis, "Organización y funcionamiento del Parlamento del futuro», en El Parlamento del siglo XXI. VIII Jornadas de la Asociación Española de Letrados de Parlamentos, Tecnos/AECPA, Madrid, 2001, p. 31. 
El objeto del presente estudio consiste en analizar la posición del parlamentario desde la perspectiva de las relaciones que entablan los sujetos mencionados. Sobre ello se han publicado numerosos trabajos, por lo que aquí se pretende no es más que una reflexión acerca de cómo las novedades legislativas, las últimas reformas operadas en los Reglamentos parlamentarios y los más recientes pronunciamientos jurisprudenciales profundizan en esa dependencia. Nos plantearemos, en primer lugar, la cuestión de las relaciones que se articulan entre los partidos políticos y los grupos parlamentarios analizando tanto el marco normativo estatal en el que se desenvuelven esas relaciones como el ámbito reglamentario fijado por las disposiciones internas de los partidos y los grupos y destacaremos el discurso de quienes apuestan por una revitalización del parlamentario individual. En segundo término, se examinarán las relaciones que mantienen los grupos parlamentarios con sus miembros destacándose las medidas a través de las cuales se materializan estas relaciones, en concreto, la disciplina de grupo y las consecuencias que acarrea sobre el irresuelto problema de la prohibición de mandato imperativo y de la titularidad del escaño. Finalmente, nos detendremos en el análisis específico de estas mismas conexiones entre partidos, grupos y parlamentarios en el contexto del Parlamento Europeo donde la inexistencia de auténticos partidos políticos y la pluralidad de mandatos matiza los haces de relaciones y la posición del diputado uti singuli.

El planteamiento inicial de estas reflexiones debe partir del contraste entre el realismo jurídico de los partidos y de la legislación cuando afronta la relación entre éstos y los partidos y el formalismo jurídico del Tribunal Constitucional al valorar la institución de la representación política declarando la autonomía del representante individual no obstante el reconocimiento de la relevancia jurídica y no sólo política de las funciones de los partidos ${ }^{4}$. Tanto la Constitución, como los Estatutos de Autonomía y los respectivos Reglamentos parlamentarios han dado cabida a esta nueva realidad reconociendo abiertamente el papel predominante de partidos y grupos parlamentarios en el funcionamiento de las Asambleas legislativas con el consecuente efecto devastador sobre el clásico mandato representativo del parlamentario individual.

La situación aboca a una paradoja: por un lado, el artículo 67.2 CE y la práctica totalidad de los Estatutos de Autonomía confirman la prohibición de

${ }^{4}$ BASTIDA FREIJEDO, Francisco J., «La función constitucional de los partidos» en Parlamento y partidos politicos. XV Jornadas de la Asociación Española de Letrados de Parlamentos, Tecnos/AELPA, Madrid, 2009, p. 22. 
mandato imperativo a favor de todos sus parlamentarios ${ }^{5}$ - prohibición que podría igualmente deducirse de lo contenido en los artículos 1.2 y 66.1 CE donde se conforma el principio de la representación nacional- y el artículo 23 CE que considera la participación en asuntos públicos — tanto si se articula de modo directo como a través de representantes - como un derecho individual de los ciudadanos. Ambos preceptos vienen a reforzar la teoría del mandato representativo que se ha visto, asimismo, confirmada en algunos pronunciamientos del Tribunal Constitucional al decir que «la elección de los ciudadanos recae sobre personas determinadas y no sobre partidos o asociaciones que los proponen al electorado" y que «la democracia participativa que la Constitución establece no queda realizada, como bien se comprende, con el sufragio irreflexivo o de otro modo desatento a la identidad de las personas que figuran como candidatos en las distintas listas electorales» (STC 167/1991, de 19 de julio, fj 4).

Por otro lado, en contraste con lo anterior, la Norma fundamental ha constitucionalizado, en su artículo 6 , a los partidos políticos a quienes atribuye importantes funciones públicas («expresar el pluralismo político», "concurrir a la formación y manifestación de la voluntad popular» «ser instrumento fundamental para la participación política») lo que condiciona el ejercicio del mandato representativo individual; además, el artículo 78.1 CE dota de rango constitucional a los grupos parlamentarios quienes se han conformado en órganos principales de la vida parlamentaria y a los que el Alto Tribunal ha reconocido legitimidad procesal e, incluso, la titularidad de los derechos garantizados en el artículo 23.2 CE a los cargos y funciones públicas argumentando que «ostentan la titularidad del derecho fundamental comprendido en el artículo 23.2 de la Constitución los propios ciudadanos, primero como candidatos a un cargo representativo y luego como parlamentarios y, en su caso, incluso los Grupos Parlamentarios en que éstos se integran y que ellos mismos constituyen» (STC 36/1990, de 1 de marzo, fj 1).

En este contexto, el reto que se plantea consiste en buscar una regulación que permita hacer compatibles varias cuestiones: las relaciones de dependencia que hay entre el partido político y el grupo parlamentario, los problemas de re-

5 Artículo 191.1 EA; art. 38.1 EAr; art. 26.1 EAst; art. 44.1 EB; art. 9.3 ECan; art. 11.2 ECant; art. 57.3 ECat; art. 10.2 ECLM; art. 22.1 ECL; art. 24.2 EEx; art. 10.3 EM; art. 26.1 EMur y art. 18.7 ER. Los Estatutos de la Comunitat Valenciana, del País Vasco y Navarra no contemplan esta prohibición. Los Reglamentos parlamentarios de la Junta de Castilla-La Mancha (art. 14); de la Asamblea de Extremadura (art. 24); del Parlamento de las Islas Baleares (art. 15); de la Asamblea de Madrid (art. 4) y de la Asamblea de Murcia (art. 5) reproducen asimismo la interdicción de mandato imperativo. 
laciones de disciplina entre ambos, el funcionamiento del grupo como elemento imprescindible de los actuales Parlamentos, la autonomía reconocida por las normas a los grupos parlamentarios y el ejercicio por los parlamentarios de sus funciones en los términos garantizados por la Constitución y los Reglamentos asegurando, en cualquier caso, la protección de los derechos que conforman el status del parlamentario individual frente a la restricción de los mismos por el grupo.

\section{LAS RELACIONES ENTRE LOS GRUPOS PARLAMENTARIOS Y LOS PARTIDOS POLÍTICOS. MARCO NORMATIVO}

La Constitución de 1978 ha introducido a la democracia española en la categoría de las democracias de partidos: el artículo 1.1 que consagra el pluralismo político entre los valores que propugna el ordenamiento jurídico se completa con el artículo 6 que establece que «los partidos políticos expresan el pluralismo político, concurren a la formación de la voluntad popular y son instrumento fundamental para la participación política». Este precepto sitúa a los partidos políticos entre las instituciones esenciales de nuestro régimen político atribuyéndoles los papeles de mediadores electorales y de gobernantes indirectos ${ }^{6}$.

Entre las funciones desarrolladas por los partidos políticos sancionadas en el artículo 6 CE destacamos en este punto la tarea de gobierno: si los partidos deben manifestar la voluntad popular en los órganos del Estado, precisan de un instrumento que realice dicha tarea con cierta eficacia. Este instrumento ubicado en el interior de los actuales Parlamentos es el grupo parlamentario ${ }^{7}$.

La realidad sociopolítica nos muestra diariamente la relación, incluso la dependencia política, del grupo parlamentario respecto al partido político pero, para el ordenamiento jurídico español y para el Tribunal Constitucional, el

${ }^{6}$ PRESNO LINERA, Miguel Ángel, Los partidos politicos y las distorsiones jurídicas de la democracia, Ariel, Barcelona, 2000.

7 La bibliografía sobre los grupos parlamentarios es amplísima. Por todos, remitimos a SAIZ ARNÁIZ, Alejandro, Los grupos parlamentarios, Congreso de los Diputados, Madrid, 1989; PÉREZ-SERRANO JAÚREGUI, Nicolás, Los grupos parlamentarios, Tecnos, Madrid, 1989; MORALES ARROYO, José María, Los grupos parlamentarios en las Cortes Generales, Centro de Estudios Constitucionales, Madrid, 1990; GARCÍA GUERRERO, José Luis, Democracia representativa de partidos y grupos parlamentarios, Congreso de los Diputados, Madrid, 1996 y a los volúmenes colectivos Los Grupos Parlamentarios, Corts. Anuario de Derecho Parlamentario, núm. 10, extraordinario, 2001 y Los Grupos Parlamentarios, Revista Parlamentaria de la Asamblea de Madrid, especial monográfico, 2007. 
grupo parlamentario no puede ser considerado un órgano del partido ${ }^{8}$. Otras razones que profundizan en la distinción entre partido y grupo son las diferentes normas que los regulan (Constitución y LO 6/2002 y Estatutos de Autonomía y Reglamentos parlamentarios, respectivamente) y el surgimiento u origen de ambos (el acuerdo de los ciudadanos y la alianza entre representantes, en cada caso). La complejidad de esta situación se ha explicado afirmando que «los grupos son la expresión de los exponentes parlamentarios de los partidos y no de sus individuos y, por consiguiente, la expresión de la voluntad popular son más los partidos políticos que los individuos comprendidos en sus listas. Consecuencia de ello es que los Grupos Parlamentarios son, a la vez, componentes orgánicos del Parlamento y subunidades de la organización de los partidos, dicho de otro modo, constituyen una penetración del partido en la estructura del Parlamento» ${ }^{9}$. La doctrina constitucionalista que ha profundizado sobre el tema ha concluido, con diferencias de matiz, que se trata de entidades autónomas creadas con fines funcionales en el interior de las Cámaras y sometidas a las normas de Derecho parlamentario y aceptan la relación fáctica que se produce entre los grupos y los partidos sin llegar a acoger la afirmación de una relación jurídica entre ambas con primacía del partido sobre el grupo ${ }^{10}$.

${ }^{8}$ El Tribunal Constitucional en su sentencia 36/1990, de 1 de marzo, en uno de los pocos pronunciamientos en los que se refiere de forma explícita a la cuestión de la naturaleza de los grupos parlamentarios, ha rechazado claramente la identidad entre grupo parlamentario y partido político al sancionar que «resulta indudable la relativa disociación conceptual y de personalidad jurídica e independencia de voluntades presente entre ambos, de forma que no tienen por qué coincidir sus voluntades». No obstante, en el ATC 12/1986, de 15 de enero, se reconoce que son los grupos parlamentarios "emanación de los partidos políticos» para distinguirlos del propio "diputado como persona física sujeto de derecho» (fj 3). En relación con esta temática, LÓPEZ GUERRA, Luis, "Parlamento y jurisprudencia constitucional», en Parlamento y consolidación democrática, J. Cano Bueso y A. Porras Nadales (coords.), Tecnos, Madrid, 1994, pp. 65-76.

9 GARCÍA PELAYO, Manuel, El Estado de partidos, Alianza Editorial, Madrid, 1996, p. 94.

10 CID VILLAGRASA, Blanca, «Naturaleza jurídica de los Grupos Parlamentarios: el Grupo Parlamentario como titular de derechos y obligaciones», en Revista Parlamentaria de la Asamblea de Madrid, monográfico sobre Los Grupos Parlamentarios, 2007, pp. 179-204. Las relaciones que, a lo largo del tiempo, se han producido entre los partidos políticos y los grupos parlamentarios han evolucionado desde, en un primer momento, el predominio de los grupos sobre los partidos; en segundo lugar, un cierto equilibrio entre ambos para, en la actualidad, caracterizarse por un evidente predominio de los partidos sobre los grupos. (DUVERGER, Maurice, Los partidos políticos, FCE, México, 2002) aunque se han apuntado los factores que tienden a reforzar la posición de los grupos respecto a su organización partidista [ONAATE RUBALCABA, Pablo, "Congreso, Grupos parlamentarios y Partidos", en El Congreso de los Diputados en España: funciones y rendimiento, A. Martínez (ed.), Tecnos, 2000, pp. 99 y 100] destacándose cómo algunos fenómenos actuales apuntan hacia un cierto cambio de tendencia en el futuro y en pro de la potenciación de los 
Por tanto, aunque no pueda afirmarse que los grupos parlamentarios son lo mismo que los partidos políticos - lo que claramente se advierte en el grupo mixto en cuya configuración se integran los parlamentarios cuyo partido político no ha alcanzado la representatividad mínima para constituir un grupo parlamentario propio ${ }^{11}$ — es obligado reconocer la conexión entre ambos entes. Esta identificación entre grupo parlamentario y partido político no encuentra respaldo en la regulación contenida en la LO 6/2002, de 27 de junio, de Partidos Políticos (LOPP, en adelante) a diferencia, por ejemplo, del Derecho alemán en el que la ilegalización de un partido implica automáticamente la pérdida de la condición de parlamentario de sus diputados por disponerlo así la Ley Electoral alemana [artículo 46(1)5 BWG]; previsión que se reitera en la legislación de los distintos Länder en relación con los representantes en las Asambleas regionales ${ }^{12}$.

Con carácter general y de modo aparente, el Derecho español no se preocupa de juridificar los contactos que por la vía de hecho se producen entre ambos aunque se advierte una tendencia a la recepción reglamentaria, legislativa, parlamentaria y jurisprudencial de estas conexiones.

\section{A) La regulación estatal y autonómica de las relaciones entre grupo y partido: Constitución, Estatutos de Autonomía y Reglamentos parlamentarios}

En primer lugar, nuestra Constitución se aleja de otros ordenamientos que no sólo proporcionan consecuencias jurídicas a la relación política entre grupos y partidos sino que pretenden convertir a los grupos en pseudo-instrumentos de los partidos políticos. Es el caso de la Constitución portuguesa cuyo artículo 163.1.c) establece que: «pierden el mandato los Diputados que se adscriban a un partido distinto de aquél por el que resultaron elegidos».

En la misma línea, el artículo 10 del Reglamento del Bundestag alemán conforme al cual «los miembros de un Grupo parlamentario deben pertenecer a un mismo partido político, pudiéndose, en ciertos casos, constituir un grupo sin cumplir este requisito si media la autorización plenaria».

grupos (RIPOLLÉS SERRANO, María Rosa, «Los grupos parlamentarios en el Senado español: 1979-2000. Análisis desde la perspectiva institucional», Corts. Anuario de Derecho Parlamentario, núm. 10, 2001, p. 297).

${ }^{11}$ Corrobora esta afirmación comprobar que, al inicio de la IX Legislatura y de manera similar a lo ocurrido en las anteriores, sólo un grupo parlamentario se encontraba conformado por un partido político exclusivamente.

12 FERNÁNDEZ HERNÁNDEZ, Antonio, Ley de partidos politicos y derecho penal: una nueva perspectiva en la lucha contra el terrorismo, Tirant lo Blanch, Valencia, 2007, p. 363. 
Precisamente, nuestro Derecho parlamentario sí ha transigido con una cierta juridificación de la relación que existe entre ambas entidades admitiendo la correlación entre el partido y el grupo. La referencia a los grupos parlamentarios conforma, según cita que incluyen todos los Estatutos de Autonomía, uno de los contenidos necesarios de los Reglamentos parlamentarios. De hecho, la naturaleza grupocrática se hace más evidente cuanto más avanzados y modernos son los Reglamentos parlamentarios puesto que profundizan en la presencia del grupo como sujeto principal de la actuación parlamentaria: es el caso del Reglamento de la Asamblea Regional de Murcia y del Reglamento del Parlamento de Cataluña (aprobados en 2005), del Reglamento de Les Corts (aprobado en 2006) y del Reglamento del Parlamento del País Vasco (aprobado en 2008) que han considerado a los grupos parlamentarios parte de la organización de la Cámara.

Si profundizamos en el análisis de estas normas, un grupo minoritario de Reglamentos parlamentarios no reconocen la relación jurídica que existe entre el grupo y el partido político puesto que parecen no contener disposición alguna que, de forma explícita, formalice tal correspondencia en el sentido de que los elegidos en la lista de una formación electoral deban integrarse necesariamente en el Grupo parlamentario que lleva su nombre (es el caso de los Reglamentos de los Parlamentos de Asturias, Canarias, Cantabria, Galicia, La Rioja, Navarra y País Vasco).

No obstante, encontramos que, bien de manera explícita bien de manera implícita, se pueden deducir dos tipos de previsiones que vienen a inscribirse en la línea de reforzamiento del binomio partido político/grupo parlamentario: en primer lugar, admitiendo una segunda vía de constitución de los grupos parlamentarios - la primera vendría determinada por la necesidad de superar una concreta mayoría de miembros para fundarlo- en la cual se exige a los parlamentarios que pretendan organizarse en grupo, expresamente y al margen de superar un porcentaje de votos, la pertenencia a una formación política que hubiere concurrido a las elecciones (artículo 23.1 RC, artículo 20.1 RA, artículo 20 RAr, artículo 23.3 RCV y artículo 22.1 RB). En segundo lugar, mediante limitaciones o prohibiciones como la impuesta a los miembros de una misma formación política de formar más de un grupo parlamentario (artículo 23.2 RC y la totalidad de Reglamentos parlamentarios autonómicos) o la de formar grupos parlamentarios diferenciados a los representantes que, al tiempo de las elecciones, no se hubieran enfrentado ante el electorado (artículo 23.2 RC y resto de Reglamentos parlamentarios autonómicos excepto los de las Cortes de Castila-La Mancha y de los Parlamentos de Cataluña, Galicia y Navarra).

Cabría añadir otros argumentos como el que nos ofrece el artículo 27.4 RS que impone a los grupos parlamentarios la obligación de llevar el nombre de las 
formaciones políticas a las que representan o, más concretamente, los artículos 24.2 RCLM, 37.1 RM y 20.3 RMur que exigen la pertenencia del diputado al grupo parlamentario correspondiente con la formación política en cuya candidatura hubiere concurrido a la elecciones y el artículo 23.2 RCV que determina que por cada partido, agrupación o coalición electoral sólo podrá constituirse un grupo parlamentario.

También se puede detectar un reconocimiento explícito de la imbricación entre el partido y el grupo a nivel legal en el modelo de financiación de los partidos políticos que consagra Ley Orgánica 8/2007, de 4 de julio, de financiación de los partidos políticos. Este modelo puede contener múltiples instrumentos que pongan en contacto o separen a los grupos parlamentarios y los partidos políticos: en la primera dirección apunta el artículo 2.1.b) de la LO 8/2007 que prescribe que son fondos de los partidos las subvenciones de los grupos parlamentarios ${ }^{13}$ que, además, deben recogerse en las cuentas de éste (artículo 9) lo que afianza el reconocimiento jurídico excepcional de un vínculo orgánico entre el grupo y el partido. Insiste en esta orientación el artículo 3.4 de la LO 8/2007 mediante la determinación de que la subvención anual para los gastos ordinarios procedentes del Estado será incompatible con la percepción de cualquier otra ayuda económica o financiera incluida en los Presupuestos Generales del Estado salvo las concedidas como compensaciones electorales y como compensaciones parlamentarias a los grupos. También tiene un contenido interesante el artículo 8 que indica que «sólo podrán resultar comprometidos por los partidos políticos hasta el 25 por 100 de los recursos procedentes de la financiación pública contemplados en los apartados b) y c) del artículo 2.1 para el pago de anualidades de amortización de operaciones de crédito». Dos consecuencias se derivan de este enunciado ${ }^{14}$ : primera, que los partidos políticos pueden utilizar los fondos obtenidos de los grupos parlamentarios conforme a sus reglas internas y, segundo, que al establecer un límite en el gasto de los partidos para una finalidad concreta, a sensu contrario el resto de pagos no se encuentra limitado más que por normas internas de las Cámaras, algunas leyes como la electoral — o las impuestas libremente por el partido. Finalmente, en el

${ }^{13}$ Este precepto viene a autorizar el desvío de los fondos que los Reglamentos parlamentarios, sin excepción, destinan a dar cobertura a la financiación de los gastos de sostenimiento y apoyo de los grupos parlamentarios y que, en realidad, son destinados a sufragar los gastos de los partidos mismos bien de forma indirecta (se contrata personal que sirve a los órganos del partido en lugar de a los del grupo) o de forma directa (se transfiere directamente el dinero a las cuentas del partido).

14 MORALES ARROYO, José Antonio, «Los efectos colaterales de la disolución de Batasuna», Revista Española de Derecho Constitucional, núm. 24, 2004, pp. 263-264. 
ámbito autonómico, resulta muy revelador el artículo 29.7 del Reglamento de las Cortes de Castilla-La Mancha cuando ordena que «Los Grupos Parlamentarios requerirán de los partidos políticos a los que se encuentren vinculados la justificación documental del destino dado a los fondos que aquéllos, en su caso, le hubieren transferido» ${ }^{15}$.

La identificación entre grupos parlamentarios y partidos políticos ha llegado a penetrar en el lenguaje empleado por las propias Cámaras que hablan de «las propuestas de los Grupos parlamentarios de una y otra Cámara pertenecientes a las mismas fuerzas políticas con representación parlamentaria» y de los cupos de representantes que «a cada fuerza política corresponde en las Cortes» ${ }^{16}$.

Por último, desde la perspectiva jurisdiccional, las controvertidas resoluciones judiciales dictadas para disolver un grupo parlamentario representante de un partido político ilegalizado inciden en esta línea de evidenciar la vinculación jurídico-formal entre el grupo y el partido: es el caso de la STS de 27 de marzo de 2003 y los AATS de 24 de abril y 20 de mayo de 2003 de ilegalización del partido Herri Batasuna y disolución de los grupos parlamentarios que figuran bajo la denominación Batasuna en los Parlamentos Vasco y Navarro y en las Juntas Generales de los Territorios Históricos de Álava, Vizcaya y Guipúzcoa, respectivamente, confirmadas por STC 85/2003, de 8 de mayo ${ }^{17}$. Al margen de otros pronunciamientos sobre ilegalización de candidaturas en diferentes procesos electorales, puede señalarse, más recientemente, la STS de 22 de sep-

15 La mayor parte de los Reglamentos parlamentarios autonómicos regulan una subvención fija y variable para todos los grupos parlamentarios incluido el grupo parlamentario mixto (en función del número de diputados); los Reglamentos parlamentarios de Asturias y Murcia no distinguen entre una y otra (art. 34.1 RAst y art. 38.1 RMur); los Reglamentos de Aragón, Baleares y Comunitat Valenciana excluyen al grupo mixto de la subvención fija (art. 26.3 RAr, art. 27.1 RB y art. 28.2 RCV) y el de Extremadura lo hace en el supuesto de que no alcance el número mínimo de diputados exigido (art. 39.3 REx) o el de Navarra el cual, para evitar el transfuguismo, excluye la subvención a los diputados del grupo mixto que se incorporen mediada la legislatura (art. 35.2 RN).

16 Texto del Acuerdo del Congreso de los Diputados sobre procedimiento de designación de los Diputados que representen al pueblo español en el Parlamento Europeo entre el primero de enero de 1986 y la celebración en España de elecciones por sufragio universal directo a tal Parlamento, aprobado por el Congreso de los Diputados el 4 de diciembre de 1985 (en PRESNO LINERA, Miguel Ángel, Los partidos políticos y las distorsiones jurídicas de la democracia..., p. 117).

17 En la misma línea jurisprudencial se inscriben las SSTS de la Sala Especial de 3 de mayo de 2003 (Elecciones municipales y autonómicas en el País Vasco de 2003); de 21 de mayo de 2004 (Elecciones al Parlamento Europeo de 2004); de 26 de marzo de 2005 (Elecciones al Parlamento Vasco de 2005) y de 5 de mayo de 2005 (Elecciones a Juntas Generales del País Vasco, autonómicas en la Comunidad de Navarra y municipales). 
tiembre de 2008 de ilegalización del partido Acción Nacionalista Vasca —confirmada por STC 31/2009, de 29 de enero-y el ATS de 16 de julio de 2009 de disolución de los grupos municipales de ANV en ayuntamientos así como el grupo de este partido en las Juntas Generales de Álava ${ }^{18}$.

La tendencia apunta, por tanto, en la dirección de fortalecer los nexos entre partidos y grupos lo que implica, a su vez, incorporar y formalizar más si cabe la presencia de los partidos en el seno de las instituciones públicas y aboca a un debilitamiento o, cuanto menos, una difuminación de la figura del representante individual. Aunque se acepte con naturalidad que, política y sociológicamente, los partidos políticos son los auténticos titulares del mandato electoral, jurídicamente esa titularidad se atribuye intuitu personae al parlamentario ${ }^{19}$. La prohibición del mandato imperativo cumple todavía hoy un importante objetivo: garantizar su independencia frente a las formaciones políticas que han promovido su candidatura y, de modo especial ante la entidad que en sede parlamentaria actúa como su emanación lógica: el grupo parlamentario. La eliminación de la prohibición del mandato imperativo conllevaría nuevos peligros ya que supondría, en la práctica, conceder la titularidad de todos los cargos públicos representativos a un reducido número de dirigentes de cada partido: una élite parecida a un nuevo soberano ${ }^{20}$ sobre cuyos excesos ya se han pronunciado reputadas voces ${ }^{21}$. No debe considerarse a los partidos políticos como verdaderos titulares de los órganos estatales ni que estén legitimados para exteriorizar directamente su voluntad puesto que la formación de la voluntad estatal requiere siempre de concretas personas físicas ${ }^{22}$.

18 VÍRGALA FORURÍA, Eduardo, «El intento de disolución del grupo parlamentario Batasuna: ¿levantamiento del velo o vulneración de derechos?», Teoría y Realidad constitucional, núm. 22, 2008, pp. 193-220 y TAJADURA TEJADA, Javier, "Constitución, Ley de Partidos y Grupos parlamentarios, en Parlamento y partidos politicos. XV Jornadas de la Asociación Española de Letrados de Parlamentos..., pp. 63-122.

${ }^{19}$ CAAMAÑO RODRÍGUEZ, Francisco, El mandato parlamentario, Congreso de los Diputados, Madrid, 1991, p. 92.

20 GARCÍA ROCA, Javier, «Los derechos de los representantes. Una regla individualista de la democracia», en La democracia constitucional. Homenaje al profesor Francisco Rubio Llorente, vol. I, Congreso de los Diputados/CEPC, Madrid, 2002, p. 856.

${ }^{21}$ MICHELS, Robert, Los partidos politicos. Un estudio sociológico de las tendencias oligárquicas de la democracia moderna, Amorrortu Editores, Buenos Aires, 1915 y VON BEYME, Klaus, La clase política en el Estado de partidos, Alianza Universidad, Madrid, 1995.

${ }^{22}$ JELLINEK, Georg, Sistema dei Diritti Pubblici Subiettivi, trad. V. E. Orlando, Società Editrice Libraria, Milán, 1912. 


\section{B) La normativa interna de los grupos y partidos: los estatutos de partido $y$ los reglamentos internos del grupo}

Las relaciones que se producen entre el grupo y el partido son desconocidas para la Constitución aunque, como hemos visto, es posible deducirlas del contenido regulado por otras normas infraconstitucionales. De vital importancia en la descripción de aquellas relaciones son las regulaciones internas de las que se dotan partidos y grupos para fijar su organización y funcionamiento interno ${ }^{23}$.

Es la propia regulación estatal la que permite que los partidos y los grupos dispongan de un margen de autonomía suficiente para adoptar el modelo de relaciones que decidan convenir.

Por lo que respecta a los partidos políticos, en cuanto asociaciones de naturaleza privada, quedan al amparo de lo dispuesto en el artículo $22 \mathrm{CE}$ y gozan de autonomía para la aprobación de sus propios estatutos aunque padezcan las limitaciones derivadas de las funciones públicas que el artículo $6 \mathrm{CE}$ les encomienda y que tienen su reflejo en numerosas condiciones como la inscripción en un registro al efecto; el sometimiento al principio de democracia interna así como a un régimen legal específico frente a otras asociaciones, determinadas especialidades de naturaleza contable; etc.

Por su parte, los grupos parlamentarios manifiestan autonomía normativa mediante la aprobación de sus reglamentos internos a pesar de que la Constitución reconoce esta autonomía a las Cámaras sobre toda la materia parlamentaria sin reconocérsela explícitamente a los grupos parlamentarios lo que no resulta extraño dada la escasa regulación referida a los mismos en el Texto fundamental y su no reconocimiento expreso en la mayoría de los Reglamentos parlamentarios ${ }^{24}$. Esta autonomía normativa de los grupos puede, sin lugar a dudas, fundamentarse en el principio general que permite a las agrupaciones dotarse de normas internas.

Además, los Reglamentos internos de los grupos parlamentarios muestran la particularidad de encontrarse limitados tanto por la Constitución como por los

${ }^{23}$ Por razones de extensión, únicamente vamos a referirnos a los Estatutos y Reglamentos internos del PSOE y del PP.

${ }^{24}$ Sólo los Reglamentos del Senado (art. 27.5), del Parlamento de Asturias (art. 34.3), del Parlamento de La Rioja (art. 25.3) y del Parlamento de Navarra (art. 35.4) reconocen, con dicción prácticamente idéntica, que «Los grupos parlamentarios gozarán de autonomía en su organización y actuación interna». Los Reglamentos del Parlamento de Canarias (art. 22.3), de las Cortes de Castilla-León (art. 21.2), de la Asamblea de Extremadura (art. 37.2), de la Asamblea de Madrid (art. 45), de la Asamblea de Murcia (art. 36) y del Parlamento Vasco (art. 25.2) determinan únicamente la obligación del Grupo Mixto de dotarse de un reglamento de organización y funcionamiento interno. 
propios Reglamentos de las Cámaras pero, también, de facto, por los Estatutos de los partidos políticos de los que los grupos puesto que aquéllos prevén esta facultad subordinada a la expresa aprobación del texto adoptado por los órganos del partido ${ }^{25}$. Sobre la base de artículos como el artículo 53.4 de los Estatutos del Partido Popular (EPP, en adelante $)^{26}$ que prevé que la organización y estructura directiva de los grupos se regirá por lo que dispongan los reglamentos elaborados por cada grupo que serán aprobados definitivamente por el Comité Ejecutivo del Partido o, más sucintamente, el artículo 81.1 de los Estatutos del Partido Socialista Obrero Español (EPS, en adelante ${ }^{27}$ que contempla la existencia del reglamento interno del grupo, los partidos políticos controlan la autonomía normativa de sus respectivos grupos parlamentarios.

Dos son las principales vías a través de las cuales los estatutos de los partidos y los reglamentos de los grupos establecen sus relaciones: una primera vía —ideológica- que consiste en la introducción en el grupo parlamentario de la línea doctrinal y política del partido y un segundo mecanismo - organizativo- constituido por las conexiones orgánicas entre el grupo parlamentario y el partido político.

a) El ideario político del partido y su recepción por el grupo

Respecto a la cuestión ideológica, el grupo parlamentario es el encargado de trasladar a las acciones parlamentarias el ideario o programa del partido que le respalda. En los Estatutos de los partidos políticos y en los Reglamentos de los grupos parlamentarios se articulan mecanismos que permiten mantener informados a los parlamentarios de las resoluciones programáticas que se adoptan en el seno del partido así como algunas medidas de control de la acción del representante individual y, en última instancia, de reacción frente a los parlamentarios indisciplinados mediante la imposición de sanciones.

Así, el artículo 38.g EPS indica que corresponde a la Comisión Ejecutiva Federal «el seguimiento de la actuación de quienes sean representantes del partido en los poderes públicos interpretando y valorando si su actuación se ajusta al cumplimiento de los objetivos fijados».

Por su parte, los EPP determinan esa influencia ideológica del partido en el grupo parlamentario exigiéndola por activa [artículo 35.1 EPP: «Los Comités

25 OLIVER ARAUJO, Joan y CALAFELL FERRÁ, Vicente J., Los estatutos de los partidos políticos españoles con representación parlamentaria, BOE/CEPC, Madrid, 2007.

${ }^{26}$ Estatutos del Partido Popular aprobados en el XV Congreso Nacional, octubre de 2004.

27 Estatutos del Partido Socialista Obrero Español aprobados en el 37 Congreso del PSOE, julio de 2008. 
Ejecutivos ejercerán las siguientes competencias: c) Definir la estrategia general del partido y sus pronunciamientos políticos y programáticos y establecer las líneas maestras de la acción política de los diversos grupos institucionales»] y por pasiva (artículo 53.3 EPP: «Los grupos institucionales atendrán su actuación a las instrucciones que emanen de los órganos de gobierno del partido»). Y resuelven que constituye una infracción muy grave «actuar en el ejercicio de los cargos públicos en forma contraria a los principios y programas del Partido o las instrucciones que emanen de sus órganos de gobierno" (artículo 11.1.c y g EPP).

Un examen de los Reglamentos internos de los grupos parlamentarios confirma asimismo la estrecha vinculación programática entre grupo y partido. El Reglamento interno del Grupo Socialista en el Congreso (RGPS, en adelante) ${ }^{28}$, establece que el funcionamiento del grupo responde al principio general de autonomía y «se orientará por los compromisos adquiridos en el programa electoral del PSOE así como por las resoluciones aprobadas en el Congreso Federal del Partido y por las directrices emanadas del Comité Federal y de la Comisión Ejecutiva Federal» (artículo 3 RGPS). Para garantizar la perfecta coordinación entre el grupo y el partido, el artículo 4 RGPS prevé que «los Diputados y Senadores del Grupo Parlamentario Socialista y de la Delegación Española en el Grupo Parlamentario del P.S.E. recibirán amplia y puntualmente información de los acuerdos políticos adoptados por los órganos de dirección del partido y con mayor detalle de aquéllos que afecten con especial intensidad a su labor parlamentaria» y el artículo 5 concreta la obligación de los diputados o senadores del GPS que formen parte de una comisión o ponencia parlamentaria de elaborar los proyectos, enmiendas, mociones y otras iniciativas parlamentarias en materia de su competencia «dando cuenta de todo ello al Comité Permanente y consultando las dudas de índole política que pudieran presentarse en la ejecución de las directrices emanadas de los organismos rectores del Partido». Finalmente, el artículo 16 RGPS señala muy claramente que «a los efectos informativos a los que se refiere el artículo 4 del presente Reglamento, se distribuirán a los parlamentarios los documentos que fijen la posición política del Partido y, cuando se considere necesario, las reuniones de cada Grupo Parlamentario incluirán un punto de información política a cargo de un miembro de la Comisión Ejecutiva Federal o del Gobierno" y el artículo 17 expone que la decisión sobre cuestiones que deban decidirse en las Cámaras corresponde al Pleno del

28 Reglamento Interno del Grupo Parlamentario Socialista aprobado por el Comité Federal los días 23 y 24 de julio de 1994 y modificado por acuerdos de 24 y 25 de marzo de 1995, de 15 de marzo de 1996, de 9 de mayo de 1996 y de 3 de septiembre de 2005. 
grupo parlamentario socialista del Congreso y del Senado «salvo que el Comité Federal o la Comisión Ejecutiva Federal hayan manifestado con anticipación una determinada directriz».

El Reglamento interno del Grupo Popular (RGPP, en adelante) ${ }^{29}$ no es tan explícito en la manifestación del sometimiento del grupo a la línea ideológica del partido aunque resulte evidente y establece en su artículo 4 el compromiso de los miembros del grupo parlamentario en la defensa de los principios y líneas básicas del programa electoral con el que concurrieron a las elecciones. Todavía, el artículo 18 RGPP aclara que «El Consejo de Dirección podrá incorporar ocasionalmente a sus reuniones a los miembros del Grupo o de la Dirección Nacional del Partido cuya presencia y participación se estime necesaria en orden a mejor atención y tratamiento de concretas cuestiones de interés para el funcionamiento del Grupo Parlamentario».

b) La simbiosis entre las direcciones del partido y del grupo

En lo que respecta a la cuestión organizativa, los Estatutos de los partidos políticos atribuyen importantes funciones a la dirección de los mismos respecto a la organización de los grupos parlamentarios.

En estas coordenadas, los EPS regulan los grupos parlamentarios en el Título VII «Del Grupo parlamentario federal del PSOE» y en el Título VIII «De los Grupos Parlamentarios de las Comunidades Autónomas y de los Grupos Socialistas en las Corporaciones Locales» y establecen que es competencia de la Comisión Ejecutiva Federal del partido la propuesta al grupo parlamentario sobre los compañeros que formarán parte de la Mesa del Congreso y del Senado así como los compañeros que formarán parte de la dirección del grupo parlamentario [artículo 38.m) EPS]. La imbricación del partido político en la organización del grupo parlamentario también se advierte en los EPP que regulan los grupos parlamentarios en el Título III bajo la rúbrica «De los Grupos Institucionales» y determinan que la convocatoria de los grupos parlamentarios la realizará el Presidente del partido, los órganos de dirección del grupo o cuando así lo soliciten dos tercios de los miembros del grupo parlamentario (artículo 53.6 EPP).

Esta regulación permite reflexionar sobre la fuerte simbiosis que existe entre las direcciones del partido político y del grupo parlamentario. La identidad de per-

29 Estatutos aprobados por los Plenos de los Grupos Parlamentarios del Partido Popular en el Congreso de los Diputados y en el Senado elegidos en los comicios generales del día 14 de marzo de 2004. 
sonas en las estructuras orgánicas sirve de conexión entre el partido y el grupo; permite la introducción de las directrices partidistas en éste y provoca, en ocasiones, que la carrera política del parlamentario discurra de forma paralela: así, la cualidad de miembro del grupo conlleva simultáneamente la concesión de un puesto relevante en el organigrama del partido $y$, a la inversa, el ocupar un puesto determinado en el partido permite la promoción a cargos en el interior del grupo. La principal consecuencia que se deriva de esta circunstancia es que condena al grupo parlamentario a la heteronimia — su dependencia de una voluntad externa- y lo convierte en una correa de transmisión de las decisiones del partido ${ }^{30}$.

En los EPS se advierte la superposición entre las direcciones del partido y del grupo en la medida en que su artículo 34 incluye como miembro nato en el Comité Federal del Partido al Presidente/a del grupo parlamentario de las Cortes Generales así como al Portavoz del grupo parlamentario socialista en el Senado. Asimismo, el artículo 40 EPS indica que participarán en la Comisión Ejecutiva Federal los portavoces del Grupo parlamentario en el Congreso y en el Senado así como el Presidente de la Delegación española socialista en el Parlamento Europeo.

Por su parte, los EPP, al margen de la identidad que reconocen en la Presidencia del partido y de los grupos parlamentarios en el Congreso, Senado y Parlamento europeo (artículo 53.5 EPP), determinan que la Junta Directiva Nacional se integre por los diputados, senadores y parlamentarios europeos (artículo 33.1 EPP) y el Comité Ejecutivo Nacional por los portavoces en el Congreso, el Senado y el Parlamento Europeo (artículo 34.2 EPP). Esquema que se reproduce a nivel autonómico: los Comités Ejecutivos Autonómicos, Provinciales o insulares contarán entre sus miembros con los portavoces en el Parlamento autonómico así como los Presidentes o, en su caso, los portavoces de las Diputaciones provinciales, de los Cabildos o Consejos Insulares (artículo 34.4 EPP). Finalmente, el artículo 35.1 EPP incluye el reconocimiento de la competencia de los Comités Ejecutivos para nombrar y cesar a los portavoces y a los cargos directivos de los grupos parlamentarios.

Los Reglamentos internos de los grupos parlamentarios confirman la regla de identidad personal entre grupo y partido. Por lo que se refiere al Director del grupo regulado en el artículo 9 RGPS que, sin duda, es el órgano más importante del Grupo porque le corresponde la dirección organizativa y política del

30 Sobre las relaciones de dependencia en las Cámaras autonómicas de los parlamentarios respecto de su grupo parlamentario y de éste, a su vez, respecto de la dirección del partido, véase ONATTE, Pablo y DELGADO, Irene, «Partidos, grupos parlamentarios y diputados en las asambleas autonómicas», en Organización y funcionamiento de los parlamentos autonómicos, P. Oñate (ed.), Tirant lo Blanch, 2006, pp. 164 a 169. 
mismo en el seno de la Cámara, autorizar cualquier iniciativa parlamentaria propuesta por uno o más parlamentarios del grupo y la adopción de cuantas medidas estime necesarias para el desarrollo de la actividad parlamentaria. Sus miembros son el Portavoz del grupo, el Secretario General y tres Secretarios Adjuntos y aclara que «La Comisión Ejecutiva Federal podrá presentar candidatos para desempeñar estos cargos». Además, el artículo 10 RGPS indica que la Comisión Ejecutiva Federal del PSOE designa, entre los miembros de los grupos del Congreso y del Senado, a los que hayan de serlo de las Mesas de ambas Cámaras. Sin embargo, quizá sea el artículo 19 RGPS el más clarificador de la identidad personal entre ambas instancias al proclamar que «El Presidente del Grupo Parlamentario Socialista podrá ser Portavoz de dicho Grupo en la Cámara. En el supuesto de que el Secretario General de la Comisión Ejecutiva Federal, por acuerdo de ésta, ostentara la Presidencia del Grupo Parlamentario de las Cortes Generales, se entenderán atribuidas al Portavoz todas las funciones previstas para el Presidente en este Reglamento». El artículo 34.a EPS advierte que el Presidente del grupo es, asimismo, miembro nato del Comité Federal del Partido.

En el caso del Grupo Popular, las relaciones entre el grupo parlamentario y el partido se canalizan a través del Comité Ejecutivo Nacional integrado por los portavoces en el Congreso, el Senado y el Parlamento Europeo (artículo 34.2 EPP) y, sobre todo, destaca la identidad que se reconoce en la Presidencia del partido y de los grupos parlamentarios en el Congreso, Senado y Parlamento europeo (artículo 53.5 EPP). Por su parte, el artículo 7 RGPP explica que la presidencia de los grupos parlamentarios «corresponde al Presidente Nacional del Partido Popular» quien propondrá al Pleno de cada grupo «al Portavoz, al Secretario General, hasta seis Portavoces adjuntos y a su Coordinador de Comisiones y al Tesorero del Grupo Parlamentario». Asimismo, el artículo 8 RGPP informa sobre la composición del Consejo de Dirección de cada uno de los grupos parlamentarios en los que se cuenta, como miembro nato, el Secretario General del Partido Popular.

\section{LAS RELACIONES ENTRE LOS GRUPOS PARLAMENTARIOS Y SUS MIEMBROS}

\section{A) La posición del parlamentario en el grupo}

La transformación del Parlamento actual en un Parlamento de grupos en sustitución del Parlamento de representantes individuales implica que éstos, con escasas y notables excepciones, carecen de visibilidad social y política. 
Observamos que la preeminencia de los grupos sobre sus miembros no se explica primariamente por las disposiciones constitucionales puesto que se constata que es escasa la regulación jurídica que les dedica el Texto fundamental: la Constitución Española los menciona sólo dos veces en el artículo 78 sobre la Diputación provincial y en el artículo 99.1 sobre el procedimiento de designación del Presidente de gobierno.

Son los Reglamentos parlamentarios los que determinan su importancia aunque pueda afirmarse que cualquiera de estas normas refleja muy levemente su arrolladora influencia ya que las causas primarias y principales de la centralidad de los grupos parlamentarios son propiamente políticas en el sentido estricto de la expresión. Esta posición de hegemonía de los grupos parlamentarios reconocida por el Derecho parlamentario plantea contradicciones en el terreno jurídico e, incluso, en el sociológico. Quizá de manera sobresaliente el de conciliar la prohibición del mandato imperativo con el funcionamiento real de las Cámaras sobre la base de grupos parlamentarios de estricta observancia disciplinaria lo que aboca a otras cuestiones como quién detenta la titularidad de representación. Los autores responden de manera distinta: desde quienes defienden que la representación corresponde a los miembros individuales de las Cámaras que cuentan con el respaldo constitucional —artículos 23.2 y 67.2 CE- además de la línea jurisprudencial afianzada por el TC hasta quienes estiman que son los grupos los verdaderos representantes del pueblo apoyándose en diferentes preceptos constitucionales pasando por quienes entienden que las líneas se superponen en un Parlamento en el que la representación corresponde a los parlamentarios que se eligen en el seno de los partidos políticos y que se expresan orgánica y funcionalmente en las Cámaras a través de grupos principalmente ${ }^{31}$.

Sobre la línea jurisprudencial adoptada por el Tribunal Constitucional, la doctrina establecida por primera vez en su sentencia 5/1983 ha sido confirmada sin excepciones en posteriores fallos recaídos sobre la cuestión aunque se suscribieron votos particulares: el derecho de participación en los asuntos públicos corresponde a los electores y a los ciudadanos y no a los partidos, por lo que no cabe la pérdida de la condición de parlamentario — al margen de los supuestos de fallecimiento o incapacidad - por causas ajenas a la voluntad del propio interesado o del electorado (STC 298/2006, de 23 de octubre, fj 8).

Desde el punto de vista sociológico, se ha dejado constancia de una conformidad abrumadora de los electores con la afirmación de que la titularidad del es-

31 GARCÍA ROCA, Javier, «Los derechos de los representantes. Una regla individualista de la democracia...». 
caño corresponde al partido o al grupo, apreciación en la que participan mayoritariamente los parlamentarios ${ }^{32}$. En otras cuestiones que afectan a la influencia de los partidos en la actuación parlamentaria y que son analizadas en el estudio del CIS sobre «La calidad de la democracia», la opinión pública se muestra más dividida: en lo relativo a la disciplina de grupo, el número de respuestas a favor de la libertad de conciencia de los parlamentarios y de la obligación de someterse a las directrices del partido es muy similar ${ }^{33}$ mientras que, en la consulta sobre la responsabilidad en la confección de las listas electorales, la apuesta se decanta decididamente por la participación ciudadana frente a la selección por los órganos internos del partido ${ }^{34}$.

Si tomásemos, de nuevo, la regulación constitucional como punto de partida para analizar la posición del parlamentario conformaríamos una imagen que no guarda correspondencia con su situación real puesto que, de los artículos 67, 68, 69 y 79 CE se deduce el protagonismo del representante individual. Las Cámaras no se componen sino de parlamentarios — diputados y senadores - de donde se sigue la expectativa legítima de todos los miembros de concurrir a todas las funciones atribuidas al Congreso y al Senado por la Constitución. Idéntica consideración de los componentes de las Asambleas legislativas de las Comunidades Autónomas se extrae del análisis de los Estatutos de Autonomía y de todos los Reglamentos de los Parlamentos autonómicos.

Lo que se deduce, a priori, es un principio de igualdad específico de los parlamentarios que tienen derecho a ejercer todas las facultades que les otorga el or-

32 ONAATE RUBALCABA, Pablo, «Congreso, Grupos parlamentarios y Partidos»..., pp. 124 y 125. El Estudio 2.588 del CIS, de 12 de enero de 2005, confirma que se mantiene esta opinión. La pregunta 23 sobre la actitud que debe adoptar el diputado que abandona el vínculo con el partido en cuyas listas se presentó se respondió por un $72,7 \%$ de los encuestados en el sentido de «abandonar su escaño para que lo ocupe otro candidato del partido en cuyas listas fue elegido» mientras que un 10,2\% apuesta por que el representante «conserve su escaño y se integre en otro grupo parlamentario». El $\mathrm{N}$ de esta pregunta es 2479.

33 Estudio 2.701, de 5 de mayo de 2007, del Centro de Investigaciones Sociológicas. Pregunta 22: «¿Con cuál de las siguientes opiniones está Ud. más de acuerdo? Los diputados deben votar siempre de acuerdo con las directrices de su partido (24,8\%). En unos temas deberían votar de acuerdo a las directrices y en otros deberían seguir su propio criterio (29,7\%). Los diputados deben seguir su propio criterio a la hora de votar aunque éste no coincida con el del partido $(31,5 \%)$ ». El N de esta pregunta es 2982.

34 Estudio 2.701, de 5 de mayo de 2007, del Centro de Investigaciones Sociológicas. Pregunta 21: «¿Quién cree Ud. que debería tener la última palabra en la selección de los candidatos de los partidos políticos? Los simpatizantes y los afiliados (20,6\%). Sólo los afiliados (18,3\%). Los órganos internos del partido (12,1\%). Todos los ciudadanos $(35,1 \%)$. El N de esta pregunta es de 2982.

(C) UNED. Revista de Derecho Político

N. ${ }^{\circ} 78$, mayo-diciembre 2010, págs. 217-256 
denamiento. Esta expectativa es válida también para el resto de competencias administrables por el grupo con la matización de la existencia de parlamentarios cualificados como es el caso del Portavoz del grupo parlamentario ${ }^{35}$.

En contra de esta impresión, el haz de facultades propias que el parlamentario puede ejercer por sí es francamente reducido y forma un catálogo menor de escaso contenido e importancia política: solicitar documentación, presentar preguntas, bien sea con respuesta escrita, bien sea con respuesta oral (tanto en Pleno como en Comisión), presentar enmiendas de detalle a los proyectos legislativos y, en su caso, iniciar las interpelaciones. Es cierto que hay algunos supuestos (presentación de la moción de censura o planteamiento de una interpelación) que pueden dar al parlamentario singular cierta relevancia política, pero distan de ser la regla y cuando tales supuestos pueden ser constitutivos de excepción se requiere una iniciativa común de una pluralidad de representantes que sólo se puede alcanzar con la aquiescencia de otros grupos.

Pero, incluso, este catálogo mínimo de funciones del parlamentario individualmente considerado es controlado por el grupo. Entre las que tienen que ver con la posición personal que ocupa en la Cámara, destaca el derecho a ejercer un voto personal e indelegable aunque matizado en ocasiones por la situación de voto ponderado a favor de los grupos parlamentarios; el derecho a formar parte al menos de una Comisión sin que en el mismo se incluya el derecho a escoger a aquélla que sea de su preferencia y el derecho a ocupar cargos en los órganos de funcionamiento de la Cámara siempre a propuesta de los grupos parlamentarios y con obligación de abandono de los mismos en caso de abandono o expulsión del grupo proponente; con el ejercicio de la función legislativa, el derecho a presentar enmiendas al articulado en proyectos y proposiciones de ley con la firma, en su caso, del portavoz del grupo parlamentario a que pertenezca y, con el ejercicio de la función de control, el derecho a solicitar documentación e información y el derecho a formular interpelaciones en ambos casos, previo conocimiento del portavoz del grupo parlamentario a que pertenezca. En resumidas cuentas, al parlamentario singular sólo se le entregan dos facultades con relevancia política material: preguntar y votar.

A estas limitaciones resta añadir la rigidez y dificultad para proceder a los cambios de grupo. En puridad, el Derecho parlamentario concede libertad a los parlamentarios para integrarse en un grupo pero exige su integración en uno que es, generalmente, el correspondiente a la formación política en cuya candidatura han concurrido a las elecciones. Aunque ningún Reglamento parlamentario exige la adscripción de manera explícita sí lo reconocen al menos por

35 REBOLLO DELGADO, Lucrecio, La Junta de Portavoces, UNED, Madrid, 1998. 
el hecho de prever la existencia del Grupo mixto al cual se adscriben los parlamentarios que no lo hagan en un grupo parlamentario determinado (artículos $25 \mathrm{RC}, 30 \mathrm{RS}$ y todos los Reglamentos parlamentarios autonómicos excepto el balear, canario, riojano, castellanomanchego y extremeño que contemplan la figura del diputado no adscrito que puede ejercer sus funciones de forma independiente).

A la vista de las reducidas competencias individuales que los Reglamentos parlamentarios atribuyen a sus miembros puede considerarse que el grupo constituye el lugar idóneo en el que estos sujetos desarrollan con plenitud sus competencias. La jurisprudencia del Tribunal Constitucional se ha hecho eco de esta realidad y ha ido virando desde una posición en la que se consideraba al representante individual el sujeto eje de la actuación de las Cámaras parlamentarias (por todas, SSTC 5 y 10/1983, de 4 y 21 de febrero) hacia un reconocimiento del papel protagonista de los grupos parlamentarios aceptando que el núcleo de la actividad parlamentaria no es el parlamentario sino agrupaciones estables de representantes que son proyección de los partidos políticos (por todas, SSTC 22/1985, de 6 de marzo; 75/1985, de 21 de junio; 163/1991, de 18 de julio). Destaca, por su contundencia, el pronunciamiento contenido en la sentencia 361/2006, de 18 de diciembre, en la que el Alto Tribunal, siguiendo una línea jurisprudencial consolidada, admite la legitimación procesal del portavoz del grupo parlamentario en defensa de los derechos fundamentales de los integrantes del grupo y subraya no sólo la posición de los grupos en el Parlamento sino su conexión con los partidos políticos: «se asume así, en el nivel jurídico, una realidad política y parlamentaria indiscutible, que es la que dichos grupos han venido desarrollando una actividad fundamental para el funcionamiento de los trabajos de las Cámaras legislativas, que no podrían darse en la actualidad sin su existencia, y sin las importantes atribuciones que, contra lo que sucedía en el pasado en unos Parlamentos que se basaban en las prerrogativas del parlamentario individual, les atribuyen los Reglamentos de aquéllas. Como proyección en las Asambleas de las distintas agrupaciones que se han enfrentado en los procesos electorales, los grupos representan un papel de gran importancia aglutinando y dando forma a las diferentes corrientes políticas presentes en las Cámaras» (fj 5).

De este modo, la pérdida de la condición de miembro de un grupo conlleva la desaparición de todas las competencias y posibilidades de acción que éste controla y poco importa que la exclusión deje intactas las competencias del parlamentario puesto que el miembro excluido pierde las ventajas de la división del trabajo y la asistencia institucional del grupo. Pero, sobre todo, es excluido de aquellos órganos del Parlamento cuya ocupación se reserva a los grupos parla- 
mentarios por el Reglamento parlamentario, es decir, las Comisiones ${ }^{36}$ con lo que la expulsión disminuye considerablemente el estatuto jurídico interno del parlamentario y sus posibilidades reales de acción.

También en el asunto financiero se descubre el condicionamiento del grupo y del partido sobre la posición jurídica del representante: el artículo 71.4 CE dispone que «los diputados y senadores percibirán una asignación que será fijada por las respectivas Cámaras» y su contenido se reitera en todos los Reglamentos parlamentarios ${ }^{37}$. Esta retribución a los miembros de las Cámaras parlamentarias se justifica y viene destinada a asegurar la autonomía y la dignidad de los representantes individuales ${ }^{38}$. No obstante, la realidad es que las asignaciones económicas que deben percibir directamente los parlamentarios coadyuvan en la suficiencia financiera de los partidos políticos ya que éstos han adoptado la práctica de recibir en una cuenta propia las retribuciones de sus miembros entregándoles posteriormente una parte de éstas previa la correspondiente deducción si bien parece más extendido el uso de exigir periódicamente el pago de un porcentaje de la asignación a la caja del partido en lo que suele llamarse irónicamente el «impuesto revolucionario».

Una evaluación del contenido de los Estatutos de los partidos políticos confirma lo anteriormente expuesto: la retribución individual del parlamentario se considera fuente de financiación del partido en el artículo 78 EPS que dispone que «las asignaciones económicas y emolumentos que perciban las personas miembro del Grupo parlamentario se ingresan automáticamente en la cuenta corriente que a tal efecto designe la Comisión Ejecutiva Federal» y en el artículo 54.2 EPP que determina que «los recursos del Partido están constituidos por (...) las contribuciones económicas de los cargos públicos en el porcentaje que se determine por el Comité Ejecutivo Nacional».

${ }^{36}$ La pertenencia a una Comisión es un derecho de todos los parlamentarios consagrado reglamentariamente (Art. 6 RC; art. 6.2 RA; art. 8.2 RAr; art. 10.2 RAst; art. 13.4 RB; art. 11.2 RCan; art. 6.3 RCant; art. 4.1 RCat; art. 11.b RCLM; art. 6.2 RCL; art. 11.2 RCV; art. 18.2 REx; art. 17 RM; art. 58.1 RMur; art. 13.2 RN; art. 10.2 RPV y art. 13.2 RR. El RS no contempla este derecho), aunque no son éstos quienes eligen su pertenencia a una determinada comisión sino que son los grupos quienes realizan esa asignación (Art. 40 RC; art. 51 RS; art. 40.1 y 2 RA; art. 48 RAr; art. 56 RAst; art. 39 RB; art. 38 RCan; art. 38 RCant; art. 40 RCat; art. 47 RCLM; art. 39 RCL; art. 40 RCV; art. 81 REx; art. 63 RM; art. 58 RMur; art. 45 RN; art. 41 RPV y art. $36 \mathrm{RR).}$

37 Artículo 8 RC; art. 24 RS; art. 8 RA; art. 9 RAr; art. 12 RAst; art. 15 RB; art. 13 RCan; art. 8 RCant; art. 8 RCat; art. 11.c RCLM; art. 8 RCL; art. 13 RCV; art. 24 REx; art. 20 RM; art. 14 RMur; art. $15 \mathrm{RN}$; art. $12 \mathrm{RPV}$ y art. $15 \mathrm{RR}$.

38 SANTAOLALLA LÓPEZ, Fernando, Derecho parlamentario español, Espasa, Madrid, 1990, p. 132. Sobre la cuestión, puede verse JIMÉNEZ APARICIO, Emilio, Régimen jurídico de las retribuciones de los Diputados y Senadores, BOE-CEC, Madrid, 1994. 
Debe, no obstante, recordarse a modo de conclusión que esta costumbre, en principio, puede basarse en la libertad de los parlamentarios que, voluntariamente, tienen la facultad de ceder su asignación parlamentaria aunque, de revocarse ese consentimiento, la negativa a ceder las percepciones encuentra apoyo en el reconocimiento constitucional y debe protegerse por los órganos de la Cámara ${ }^{39}$.

\section{B) La disciplina de voto}

El grupo parlamentario requiere de unidad de actuación para conseguir sus objetivos y la coordinación de los trabajos parlamentarios. Esta unificación de voluntades se obtiene, principalmente aunque no sólo, a través de la disciplina de grupo que va mucho más allá de la disciplina de voto abarcando asimismo el contenido de las iniciativas parlamentarias (preguntas, interpelaciones, enmiendas,...) y las intervenciones y defensas efectuadas en el interior de los órganos del Parlamento (ponencias, comisiones, diputaciones permanentes,...). A través del grupo parlamentario, a su vez, los partidos políticos mantienen una férrea disciplina sobre el comportamiento de los parlamentarios.

En última instancia, la coordinación se impone reforzándose con medidas disciplinarias siendo la más grave la expulsión del grupo lo que plantea la problemática de la titularidad del escaño. En un primer acercamiento, el principal motivo por el que se deja de ser miembro de un grupo parlamentario es a causa de la pérdida de la condición de parlamentario. Sólo los miembros que integran la Cámara pueden formar parte de un grupo parlamentario constituido en la misma por lo que la pérdida del escaño acarrea inevitablemente la pérdida de la condición de miembro de un grupo. Las causas que implican la pérdida de la condición de parlamentario son: una decisión judicial firme que anule la elección o proclamación, la condena por inhabilitación en sentencia judicial firme, el fallecimiento o la incapacitación judicial, la extinción del mandato y la renuncia ante la Mesa de la Cámara ${ }^{40}$.

39 HOLGADO GONZÁLEZ, María, La financiación de los partidos políticos, Tirant lo Blanch, Valencia, 2003.

40 Art. 22 RC; art. 19 RA; art. 6 RAr; art. 25 RAst; art. 9 RB; art. 8 RCan; art. 20 RCant; art. 17 RCat; art. 9 RCLM; art. 18 RCL; art. 10 RCV; art. 17 REx; art. 14 RM; art. 12 RMur; art. $28 \mathrm{RN}$; $23 \mathrm{RPV}$ y art. $12 \mathrm{RR}$. El artículo $18 \mathrm{RS}$ contempla, además, la pérdida por comunicación de las Asambleas legislativas de las CCAA en el caso de los senadores designados. En el ámbito autonómico se añade la pérdida de la condición de aragonés (art. 6.d RAr); de la condición de vasco (art. 23.6 RPV); la aceptación de su designación como senador representante de la Comunidad (art. 8.5 RCan) o la comisión de una falta muy grave (art. 9.7 RCLM). 
La cuestión de la disciplina y los modos de sancionarla presenta unos perfiles diversos cuando la ejerce el partido político sobre sus afiliados o cuando lo hace el grupo parlamentario sobre sus miembros. El ordenamiento jurídico ha admitido la disciplina del partido político sobre la actuación del afiliado puesto que, teóricamente, la decisión procede de los órganos competentes del partido los cuales, asimismo, responden en su organización y funcionamiento a los principios de democracia interna (artículo 6 CE y artículo 7 LOPP).

Asimismo, son de sobra conocidos los efectos sancionatorios que los Reglamentos internos de los grupos contemplan para sus miembros: de tipo pecuniario en el caso de incomparecencia al Parlamento y de carácter dimisionario del cargo por incumplimiento de los deberes políticos. Este último supuesto plantea fricciones constitucionales con el artículo 67.2 CE que prohíbe el mandato imperativo y el artículo 71.1 CE que sanciona la inviolabilidad de los diputados y senadores por las opiniones manifestadas en el ejercicio de su función.

El contraste es evidente: según el artículo $6 \mathrm{CE}$, la creación de los partidos políticos es libre dentro del respeto a la Constitución y a la ley y no hay estatuto que no contradiga lo establecido en el artículo 67.2 CE que sanciona la prohibición de mandato imperativo además de restringir notablemente el ejercicio del derecho del representante, consagrado en el artículo 23.2 CE, a través del control del estatus funcional y económico del cargo público y de los grupos parlamentarios en los que se integra. Lo que no impide —según denuncia Bastida ${ }^{41}$ - la inscripción del partido político en el respectivo registro.

Por lo que se refiere al mandato de partido y a la cuestiones disciplinarias, en el caso del PSOE, quienes sean miembros del grupo parlamentario están obligados a acatar la declaración de principios y resoluciones aprobadas en el Congreso Federal del partido y en el ejercicio de sus funciones aplicarán las resoluciones y acuerdos adoptados expresamente por los órganos de dirección del partido (artículo 75 EPS). Especialmente directo es el artículo 77 EPS que establece la disciplina de voto de los miembros del grupo parlamentario «en todos los casos». De no respetarla, se atribuye al Comité Federal del partido, no al grupo parlamentario, la facultad para proceder a darle de baja, previo expediente incoado por un órgano del partido, no del grupo: la Comisión Federal de Garantías. La relación de disciplina entre grupo y partido se completa, en primer lugar, con el artículo 53.1.a) EPS que determina que si se produce el abandono del grupo, el individuo es expulsado del partido y, en segundo término, con el artículo 79 que establece que «a los efectos orgánicos los integrantes del grupo continuarán vinculados a sus unidades orgánicas respecto a sus actividades en el Parlamento».

${ }^{41}$ BASTIDA FREIJEDO, Francisco J., «La función constitucional de los partidos»..., p. 33. 
El RGPS traslada el mantenimiento de la disciplina en el seno del grupo al partido: en primer lugar, como vimos, el artículo 16 RGPS señala que "se distribuirán a los parlamentarios los documentos que fijen la posición política del Partido»; en segundo término, el artículo 17 precisa que determinadas cuestiones sobre las que deban pronunciarse las Cámaras se decidirán con anticipación en directrices manifestadas por el Comité Federal o la Comisión Ejecutiva Federal; finalmente, el artículo 33 RGPS dispone que «el Comité Director podrá sancionar la emisión del voto contrario a la orientación acordada por el Grupo, cuando ésta se haya realizado de forma voluntaria y haya sido manifestada explícitamente, sin perjuicio del mecanismo disciplinario previsto en los Estatutos Federales del PSOE».

El Partido Popular, por su parte, dictamina en el artículo 53 EPP que los grupos institucionales del Partido Popular son la vía para la acción política del partido en las diversas instituciones de ámbito nacional, autonómico, provincial, insular y local y atendrán sus actuaciones a las instrucciones que emanen de los órganos directivos del Partido. La quiebra de estas obligaciones podrá dar lugar a un procedimiento sancionador conllevando, en su caso, la expulsión del partido (artículo 9.b EPP).

Finalmente, en los Estatutos de los partidos políticos se exhorta a la devolución del acta al partido en caso de abandono del mismo, mecanismo claramente ineficaz por inconstitucional. En el artículo 76 EPS se declara que «todas las personas miembros del Grupo parlamentario aceptan el compromiso de presentar su dimisión al Presidente/a del Parlamento si una vez elegidas causasen baja en el PSOE por cualquier circunstancia». De forma más eufemística, en el artículo 7 EPP consta la obligación de «devolver al Partido la representación institucional que ostenten en nombre de éste cuando se den de baja voluntariamente».

La fricción es notable asimismo con la jurisprudencia del Tribunal Constitucional sobre el «concepto de cargo público representativo» elaborado a partir de las sentencias 5 y 10/83 donde considera como núcleo esencial del derecho de representación el «ius in officium» —denominación doctrinal de la que se apropia la STC 161/1988, de 20 de septiembre-y precisa que se produce una lesión de este derecho cuando se limita el ejercicio de la representación política ${ }^{42}$.

${ }^{42}$ Sobre la construcción jurisprudencial del derecho de representación, puede verse PULIDO QUECEDO, Manuel, El acceso a cargos y funciones públicas, Civitas, Madrid, 1992, pp. 251 y ss.; GARCÍA ROCA, Javier, Cargos públicos representativos. Un estudio del artículo 23.2 de la Constitución, Aranzadi, Navarra, 1999, pp. 39 y ss. y FOSSAS ESPADALER, Enric, El derecho de acceso a los cargos públicos, Tecnos, Madrid, 1996, pp. 51 y ss. 
Jurisprudencia constitucional que ha avalado la práctica del transfuguismo parlamentario y ha obligado a pactos extraparlamentarios entre las formaciones políticas para expulsar a los tránsfugas ${ }^{43}$.

En estos pronunciamientos, ratificados una década más tarde en la STC 31/1993, de 26 de enero, sostiene el Alto Tribunal que el sufragio pasivo cobra sentido como correlato del sufragio activo de los electores y que únicamente quien crea una relación jurídica de representación puede poner fin a la misma y no una tercera voluntad ajena a la manifestación del sufragio aunque participe activamente en el proceso electoral a través de la presentación de candidaturas. A la vez, y con respecto al parlamentario individual que decide votar en conciencia y separarse del voto de partido, el obligado respeto del contenido esencial del derecho fundamental al desempeño de los cargos públicos para los que los parlamentarios han sido elegidos, provoca que el ejercicio del derecho de voto se vea constitucionalmente protegido por la garantía de la inviolabilidad (entre otras, SSTC 51/1985, de 10 de abril; 243/1988, de 19 de diciembre; 30/1997, de 24 de febrero y $110 / 2000$, de 5 de mayo).

Sorprendentemente, en estos mismos fallos, se reconoce la plena eficacia del mandato de partido al declarar que los partidos «no son órganos del Estado, por lo que el poder que ejercen se legitima sólo en virtud de la libre aceptación de los estatutos, en consecuencia, sólo puede ejercerse sobre quienes, en virtud de una opción personal libre, forman parte del partido» (STC 10/1983, de 21 de febrero, fj 3), línea en la que profundizan los votos particulares de la sentencia favorables a reconocer el sometimiento de la militancia a las directrices partidistas. Todo ello obliga a partir de un aspecto fundamental: el del sometimiento libre y voluntario del representante a la disciplina parlamentaria de partido. A partir de estas argumentaciones, puede concluirse que son constitucionales las sanciones que imponen los grupos parlamentarios - multas, amonestaciones,...- incluso las de ámbito interno que implican la expulsión del mismo o del partido pero con el límite de que la exclusión del grupo no conlleve la pérdida del status de parlamentario ${ }^{44}$ puesto que la titularidad del escaño constituye el único dominio que le resta al representante frente a la «voracidad» de los partidos.

El sistema jurídico debe garantizar un mínimo parlamentario básico al representante individual y ese mínimo se centra en la indisponibilidad del escaño. No resulta lógico que en un sistema jurídico rigurosamente garantista en

43 TOMÁS MALLÉN, Beatriz, Transfuguismo parlamentario y democracia de partidos, CEPC, Madrid, 2002, pp. 99-103.

44 SÁIZ ARNÁIZ, Alejandro, Los grupos parlamentarios..., p. 237. 
materia de derechos fundamentales, la representación política — como corolario de un derecho fundamental— quede supeditada en función del dominio del grupo ${ }^{45}$.

Concluyendo: la disciplina de voto, el pago de multas, el desvío de fondos económicos,... pueden ser siempre rechazados por el parlamentario puesto que la intención de hacer valer aquellas pretensiones tendrían nula eficacia jurídica ${ }^{46}$. Otra cosa es que «en qué medida esté dispuesto (el parlamentario) a hacer uso de esa garantía es una decisión personal en la que se sopesarán las lealtades, valores y roles en conflicto así como los costes políticos de la decisión entre los que, en la mayor parte de los casos, se contará la exclusión de la clase política" ${ }^{37}$. Como se sabe, los casos de indisciplina en los que el parlamentario se aparta de las directrices del grupo o no se somete a sus indicaciones son infrecuentes.

A pesar de este análisis, se observa que algunos Reglamentos parlamentarios han refrendado la dependencia del acta de diputado de la decisión del grupo. Los Reglamentos de la Asamblea Regional de Murcia (artículo 35.1.b) y de la Asamblea de Madrid (artículo 43.1.b) permiten la expulsión del diputado «por decisión del Grupo Parlamentario» notificada expresamente a la Mesa por el Portavoz del Grupo Parlamentario correspondiente. El Reglamento de las Cortes Valencianas contempla, asimismo, esta facultad del grupo parlamentario pero «deberá acreditarse ante la Mesa de Les Corts que la decisión de expulsión fue adoptada, al menos, por decisión de la mayoría absoluta del mismo» (artículo 27.2).

Estas previsiones, por un lado, acogen la exigencia de democracia interna que constitucionalmente se impone a los partidos políticos y, por extensión, a los grupos parlamentarios de modo que la expulsión de un grupo debe hacerse mediante un proceso democrático: el grupo ha de comunicar a la Mesa la decisión colectiva para que ésta sea eficaz y legítima. Por otro lado, priorizan la centralidad del programa político en torno al cual se define el grupo parlamentario. En él se integran los miembros que se comprometen con tales objetivos. En consecuencia, cuando quiera que un parlamentario no se identifique por más tiempo con el programa o con los acuerdos de debate y votación hasta el extremo de apoyar sistemáticamente grupos antagónicos, es correcta la separación del grupo.

En teoría, esta regulación permite que la decisión de expulsión de un miembro del grupo pueda someterse a un control de regularidad reglamentaria pues-

45 CAAMAÑO RODRÍGUEZ, Francisco, El mandato parlamentario..., p. 59.

46 PRESNO LINERA, Miguel Ángel, Los partidos politicos y las distorsiones jurídicas de la democracia..., pp. 150-151.

47 GARCÍA PELAYO, Manuel, El Estado de partidos..., p. 100. 
to que la normativa interna de grupos y partidos, en virtud de la potestad de autoorganización que comprende el derecho de asociación, detallan las causas y procedimientos de expulsión de los miembros. Mas, en la práctica, la pérdida del mandato por expulsión del grupo/partido plantea el problema de la dificultad en su control puesto que se trata de una cuestión intrínsecamente conectada al funcionamiento interno de estas organizaciones rebasando las posibilidades de ordenación y racionalización del Derecho. Se trata de un conflicto estrictamente político que presenta, además, la problemática del órgano al que correspondería su resolución: en el caso de optarse por la propia Cámara se corre el riesgo de que se resuelva la propuesta en función de cómo quedarían conformadas las nuevas mayorías políticas en su seno y en el supuesto de confiar en el Poder Judicial se está sometiendo a su juicio una causa estrictamente política con el riesgo de judicialización de ésta ${ }^{48}$.

Se trata, en definitiva, de buscar un equilibrio entre el mantenimiento de un mínimo de funcionalidad en la organización y funcionamiento de la institución y el respeto de las garantías innatas propias del status del parlamentario. No se descubre nada al afirmar que sería imposible el funcionamiento de los órganos superiores del Estado si los miembros que integran el legislativo pudiesen adoptar, a su albedrío y sin instrucciones superiores, las decisiones que estimasen personalmente adecuadas en ejercicio de un mandato libre que, como sabemos, no ha existido jamás en su plenitud ${ }^{49}$. El predominio de las directrices de los órganos de liderazgo de los partidos políticos sobre los representantes es obligado en términos de eficacia y lógica de funcionamiento. Pero esta lógica de ninguna manera puede constreñir de manera irrazonable el conjunto de competencias que conforman el derecho al cargo público.

\section{PARTIDOS, GRUPOS Y DIPUTADOS EN EL PARLAMENTO EUROPEO: LA PLURALIDAD DE MANDATOS}

Introducimos, en este último apartado, unas breves reflexiones sobre las peculiaridades que presenta la relación entre partidos, grupos y representantes a nivel europeo. El Parlamento Europeo se inserta en un conjunto orgánico, el de la Unión Europea, marcado por principios sui géneris. Ha sido habitual hablar del déficit democrático de la Unión identificándolo con un déficit del Parla-

48 CAAMAÑO RODRÍGUEZ, Francisco, El mandato parlamentario..., p. 273.

49 PITKIN, Hanna J., El concepto de representación, Centro de Estudios Constitucionales, Madrid, 1985, pp. 160-161. 
mento, cuestión que se ha tratado de corregir en el Tratado de Lisboa cuya entrada en vigor se produjo el 1 de diciembre de 2009.

Por lo que a nuestra investigación afecta, el Parlamento Europeo padece de algunas carencias estructurales, que lo hacen diferente a un Parlamento nacional, cual es la inexistencia de un elemento vertebral del principio democrático, como son los partidos políticos europeos y su sustitución por los grupos políticos del Parlamento que ejercen el protagonismo en detrimento de aquéllos ${ }^{50}$.

El nuevo artículo 8.A.4 TUE, en la redacción que le otorga el Tratado de Lisboa, menciona a los partidos políticos a escala europea lo que viene a significar aquellos partidos políticos que trascienden las fronteras nacionales, que elaboran listas únicas para toda la Unión Europea y que defienden en sus programas electorales asuntos de carácter transversal, de interés para todos los ciudadanos europeos, independientemente del Estado al que pertenezcan, es decir, partidos que no son los que se encuentran hoy en el seno del Parlamento Europeo. Los partidos políticos nacionales son los que suplantan en muchas de las funciones a los inexistentes partidos políticos europeos que aparecían mencionados sin mucha convicción en el artículo I-46.4 del inédito Tratado Constitucional que establece que «Los partidos políticos de dimensión europea contribuirán a la formar la conciencia política europea y a expresar la voluntad de la Unión» y en el artículo III-331 que evita reiteraciones y expresa que «La Ley europea regulará el Estatuto de los partidos políticos de dimensión europea a la que se refiere el apartado 4 del artículo I- 46 y, en particular, a las normas relativas a su financiación».

Las causas de la inexistencia de partidos europeos — se habla de partidos políticos en Europa - son dos. Por un lado, los representantes electos al Parlamento Europeo ya pertenecen a una estructura partidaria — nacional — por lo tanto, no están urgidos a crear una nueva organización, toda vez que su designación y responsabilidad se remiten a una organización preexistente. Por otro lado, dado el escaso poder del Parlamento Europeo en lo relativo tanto a las atribuciones legislativas como a las facultades de control sobre la rama ejecutiva de la Unión Europea, existe una mínima posibilidad de desarrollar una relación gobiernooposición como dinámica normal de funcionamiento ${ }^{51}$. Más bien se observa una

50 NINATI, Stefania (2005): «La fórmula parlamentaria europea. Desde sus orígenes hasta el Tratado Constitucional», en Constitución Europea y Constituciones Nacionales, M. Cartabia, B. de Witte y P. Pérez Tremps (dirs.), Tirant lo Blanch, Valencia, 2005.

${ }^{51}$ MALAMUD, Andrés, "Los partidos políticos en la Unión Europea: una contradicción en los términos», http://www.iue.it/Personal/Researchers/malamud/Partidos\%20politicos\%20en\% 20la\%20UE\%20(RACP).pdf. 
tendencia creciente hacia la cooperación entre grupos parlamentarios. En realidad, las diversas tareas que los partidos desarrollan a escala nacional son llevadas a cabo, en el espacio europeo, por otras instituciones y organizaciones: así, la movilización y expresión de la voluntad popular son canalizados a través de los partidos nacionales; el reclutamiento del personal político y burocrático es realizado por los gobiernos nacionales y las instituciones europeas; y el proceso de toma de decisiones es ejecutado por organismos no partidarios, como el Consejo y la Comisión Europea, e influenciados por grupos de interés y de presión antes que por partidos.

Según dispone el artículo 30 del Reglamento del Parlamento Europeo de julio de 2009 (RPE, en adelante), en la Eurocámara los diputados se reúnen en grupos políticos: no se agrupan por nacionalidades, sino en función de sus afinidades políticas ${ }^{52}$. El Parlamento no necesita normalmente evaluar la afinidad política de los miembros de un grupo: cuando se constituye un grupo político, los miembros del mismo aceptan por definición que existe una afinidad ideológica entre ellos. Sólo es preciso que el Parlamento evalúe si el grupo se ha constituido de conformidad con el Reglamento cuando los diputados interesados nieguen tal afinidad. El número de diputados necesario para constituir un grupo es de veinticinco y en cada uno debe estar representada al menos la cuarta parte de los Estados miembros. Está prohibido pertenecer a más de un grupo político (artículo 30.4 RPE) y algunos diputados no pertenecen a ninguno: forman parte de los no inscritos (artículo $33 \mathrm{RPE}$ ). La posición adoptada por cada grupo se determina por concertación en su seno explicitándose que ningún diputado miembro de un grupo puede recibir un mandato obligatorio de voto (artículo 2 RPE).

La situación de los eurodiputados en lo que concierne a las funciones parlamentarias tradicionales difiere poco de la de los parlamentarios nacionales y autonómicos: configurado el Parlamento Europeo como una asamblea grupocrá-

52 En la actualidad, tras las séptimas elecciones europeas celebradas en junio de 2009, los dos grupos mayoritarios en el Parlamento Europeo son el Popular y la alianza de los Socialistas y Demócratas, con 265 y 184 diputados respectivamente. El resto de grupos son el liberal (Alianza de los Demócratas y Liberales por Europa) con 84 diputados; los verdes (Verdes/Alianza Libre de Europa) con 55 diputados; los comunistas (Izquierda Unitaria Europea/Izquierda Verde Nórdica) con 35 miembros; el Grupo Conservadores y Reformistas Europeos (que integra a partidos de ideología conservadora y euroescéptica) con 54 diputados; el Grupo Europa de la Libertad y de la Democracia con 32 miembros; y el de los No inscritos (equivalente al Grupo Mixto español) con 27 inscritos. En total, 736 diputados. Desde las elecciones europeas de 1989, se advierte que se reduce la fragmentación de grupos políticos en el Parlamento Europeo (de once a los ocho actuales) debido a una ampliación del espectro ideológico que comprende cada uno de ellos. 
tica, el RPE reconoce al representante europeo principalmente, el derecho de voto (artículo $164 \mathrm{RPE}$ ), el derecho a formular preguntas escritas (artículo 117 RPE) y el derecho de acceso a documentos y a información (artículo 148 RPE). En lo demás, se reproduce el protagonismo de los grupos políticos para la mayoría de las actividades parlamentarias. Así, el grupo político mediatiza la presentación de candidatos para integrar las Comisiones permitiéndose el nombramiento de suplentes mediante notificación antes del comienzo de la votación (artículo $186 \mathrm{RPE}$ ) y protagoniza, como no podía ser de otra forma, la composición de la significativa Conferencia de Presidentes — equivalente a la Junta de Portavoces- (artículo 24 RPE). Finalmente, para el ejercicio de relevantes funciones parlamentarias se reconoce la legitimidad de actuación a cuarenta diputados o a un grupo político: presentación de candidaturas para la Presidencia y Vicepresidencia (artículo $13 \mathrm{RPE}$ ); derecho de presentación de enmiendas en las propuestas legislativas de la Comisión (artículo 60 y siguientes RPE); tramitación de los tratados y acuerdos internacionales (artículos 89 y $90 \mathrm{RPE}$ ); presentación de propuestas de resolución en la elección de los miembros de la Comisión, del Tribunal de Cuentas o del Comité Ejecutivo del Banco Central Europeo (artículos 106, 108 y 109, respectivamente); propuestas de resolución a las Declaraciones de la Comisión, el Consejo y el Consejo Europeo (artículo $110 \mathrm{RPE}$ ), presentación de preguntas orales (artículo $115 \mathrm{RPE}$ ); propuestas de modificación del orden del día (artículo $140 \mathrm{RPE}$ ); presentación de enmiendas de índole legislativa (artículo $156 \mathrm{RPE}$ ); composición de las comisiones proporcional a su importancia en la composición total del Parlamento (artículo 186 $\mathrm{RPE}$ ) y presentación de propuestas de enmienda o modificación al proyecto presupuestario (Anexo V, artículo 3.2).

Al hilo de los planteamientos anteriores puede resultar interesante conocer las previsiones contenidas en los Reglamentos internos de los grupos políticos: estas normas vendrán a confirmar la subordinación del parlamentario individual al grupo. Como muestra, el Reglamento del Grupo Socialista Europeo de abril de 2003 (RGSE, en adelante) ${ }^{53}$ determina que el grupo decide sobre la distribución global del tiempo de uso de la palabra que le corresponda en cada debate, redactará la lista y establecerá el tiempo de uso de la palabra de los oradores que intervendrán en nombre del Grupo (artículo 40 RGSE), dispondrá sobre la presentación, en su nombre, de las preguntas orales con debate, de las propuestas de resolución con solicitud de debate de actualidad y de urgencia y las declaraciones inscritas en el registro, de las propuestas de reso-

53 Este Reglamento será adaptado en breve para la nueva Alianza de Socialistas y Demócratas en el Parlamento Europeo. 
lución remitidas a Comisión y de las preguntas para el turno de preguntas. Las preguntas escritas se remitirán a la Secretaría del Grupo para su conocimiento (artículo 41.2, 3 y 6 RGSE). O, más escuetamente, el artículo 25 del Reglamento del Grupo del Partido Popular Europeo de junio de 2009 (RGPPE, en adelante) que obliga a los miembros del grupo a informar con antelación a la Presidencia y al coordinador responsable acerca de las iniciativas legislativas relativas a actos comunitarios.

Pero la posición del diputado europeo refleja un estado particular en lo que respecta a su vínculo ideológico o partidista ya que su candidatura para las elecciones al Parlamento Europeo aparece en listas elaboradas por partidos nacionales que concurren a los comicios y, una vez obtenido el escaño, el representante se integra en un grupo político en el seno de la Eurocámara con lo que recibe - como mínimo - una doble vinculación: la que mantiene con el partido de ámbito estatal en cuyas listas concurrió y la que se establece con el grupo político europeo cuyas directrices, en muchas ocasiones, pueden no resultar coincidentes. Esta circunstancia, unida a la que apuntábamos más arriba de inexistencia de un planteamiento Gobierno/oposición en el Parlamento Europeo- todavía muy mediatizado por los Estados miembros - hace suponer que la disciplina de partido que impera en las democracias occidentales tenga una versión menos partidaria y más nacionalista en la Unión Europea.

En este sentido y en primer lugar, el RPE reproduce para los europarlamentarios la prohibición del mandato obligatorio de voto (artículo 2). Se observa, no obstante, que los Reglamentos internos de los grupos políticos exigen el sometimiento del eurodiputado a las directrices emanadas de los respectivos grupos aunque añadiendo la posibilidad de excepcionarse. Así, el artículo 6 RGPPE reconoce que «Los miembros se comprometen a apoyar, como norma, a línea del grupo en las votaciones; no obstante tienen el derecho de votar de acuerdo con su conciencia y sus convicciones políticas. Cuando tengan la intención de no votar de acuerdo con la línea del Grupo en un asunto de importancia, deben informar al Presidente del Grupo o a la Asamblea plenaria del mismo el día antes de la votación». El RGSE, tolera asimismo, la separación de la disciplina de grupo en el artículo 36.2 donde reconoce que «Aquellos diputados que, con anterioridad a la votación, hayan expuesto graves motivos políticos que les lleven, llegado el caso, a no sumarse a la decisión de la mayoría, no quedarán vinculados por dicha decisión».

Estos planteamientos teóricos acerca del doble vínculo ideológico que se establece entre los eurodiputados y su grupo político y entre aquéllos y el partido nacional son confirmados por la práctica en la actividad de los grupos en el Parlamento Europeo aunque sin presentar resultados extremos. Un completísimo 
estudio de la organización Votewatch ${ }^{54}$ analiza los diferentes índices de cohesión en los grupos políticos europeos y en las delegaciones nacionales y arroja algunas conclusiones definitivas de las que resaltamos dos. En primer lugar, el índice de cohesión entre los grupos políticos europeos — que mide la frecuencia con la que el grupo vota en bloque con independencia de las líneas mantenidas por los partidos nacionales - muestra un elevado porcentaje de unidad en cinco de los siete grupos políticos europeos ${ }^{55}$. En segundo término, el índice de cohesión de las delegaciones nacionales - que indica la frecuencia con la que estas delegaciones votan en bloque con independencia de sus afiliaciones en los grupos políticos europeos- señala que todas las delegaciones — con excepción del Reino Unidopriorizan con mayor asiduidad las directrices nacionales sobre las europeas ${ }^{56}$. El balance que arroja este estudio viene, por tanto, a resaltar la existencia de un «estigma» nacional sobre el Parlamento Europeo.

El mandato o disciplina de grupo tiene conexiones evidentes con el poder de coerción de los grupos a través de la imposición de medidas disciplinarias. Precisamente, el quebrantamiento reiterado de la disciplina impuesta por los grupos políticos - entre otros motivos, por priorizar las directrices nacionales - puede acarrear la expulsión del parlamentario, previsión que contemplan en sus Reglamentos internos. En el caso del Grupo del Partido Popular Europeo se determina que «la Asamblea plenaria puede decidir sobre la exclusión de un miembro por votación secreta. En este caso, la propuesta de exclusión deberá someterse a todos los miembros del Grupo por escrito tres días, como mínimo, antes de la votación, se oirá la opinión de los miembros de la misma nacionalidad que el miembro en cuestión y se adoptará la decisión por mayoría de dos tercios de los votos emitidos siempre que participen en la votación al menos la mitad de los miembros» (artículo 7 RGPPE). El Reglamento del Grupo de la Alianza de los Demócratas y Liberales por Europa de febrero de 2009 (RALDE, en adelante) contempla asimismo la posibilidad de la expulsión del grupo de los di-

${ }^{54}$ http://www.votewatch.eu/cx_epg_coalitions.php.

55 El Grupo Los Verdes obtiene el índice más elevado de cohesión (0.9 sobre 1) seguido de PSE (0.88); ALDE (0.86); PPE-DE (0.85); GUE-IGL (0.82); UEN (0.72); IND/DEM (0.4) y NI $(0.4)$.

56 Eslovenia lidera el índice de cohesión de su delegación nacional (0.75) mientras que el Reino Unido ocupa el último lugar en el escalafón y es el único país que «suspende» (0.48). España presenta un índice de cohesión de 0.68. La reelección, el pasado 16 de septiembre de 2009, de José Manuel Durao Barroso como Presidente de la Comisión Europea ha proporcionado un claro ejemplo de la superioridad del vínculo nacional sobre el europeo: los representantes españoles en el Grupo Socialista votaron a favor de la candidatura desmarcándose de la dirección de voto del Grupo en la Eurocámara que optó por la abstención. 
putados que no procedan de los partidos que conforman la Alianza y en su artículo 2.4 exige que, por mayoría de dos tercios, el Grupo decida la expulsión. La expulsión del grupo, obviamente, no comporta la retirada del acta de eurodiputado sino que fuerza al representante a ingresar en otro grupo o su pase a la categoría de no inscrito. El Reglamento de la Eurocámara, por su parte, sí contempla la posibilidad de retirar el mandato del diputado como consecuencia de la sanción propuesta por el Presidente de la Cámara ante la Conferencia de Presidentes (artículo 153.3.d RPE).

Finalmente, resta por considerar cómo se produce, a nivel europeo, la vinculación orgánica entre los partidos y los grupos. Este vínculo presenta también notables diferencias respecto a la que se manifiesta en los Parlamentos nacionales y autonómicos: en el caso europeo es evidente que, dados los múltiples partidos nacionales que integran el grupo político europeo, no cabe hablar de simbiosis ${ }^{57}$. La concurrencia de cargos se limita a la composición de algún órgano directivo del grupo como la Mesa que, en el caso del Grupo del Partido Popular Europeo, estará compuesta por el Presidente y el Secretario General del PPE, siempre que sean diputados al Parlamento Europeo (artículo 15.1.f RGPPE) así como los Presidentes de las delegaciones nacionales (artículo 15.1.b RGPPE). En caso de que el Presidente y el Secretario General del PPE no fueran diputados al Parlamento Europeo, asistirán con carácter permanente a las reuniones de la Mesa en calidad de invitados ad personam (artículo 15.2). También el RGALDE admite que, entre los miembros de la Mesa, se encuentre «un representante designado por cada partido» (artículo 9.1.c RGALDE). Los presidentes así como los secretarios de los partidos que conforman ALDE serán invitados a las reuniones del Grupo cuando los asuntos conciernan a estos partidos (artículo 13.4 RGALDE).

57 Por lo que respecta a la inserción que a nivel nacional se advertía entre las estructuras del partido político y del grupo parlamentario con un equilibrio entre ellas y la acumulación de cargos en las mismas personas es difícil que se reproduzca en el Parlamento Europeo debido a la primacía que los partidos por la política nacional-estatal de forma que, generalmente, bien «se desplaza al Parlamento Europeo a quienes se encuentran en una segunda fase de su actividad política» o, «como ocurre en el caso de Italia, los mismos líderes nacionales encabezan las listas europeas para aprovechar su tirón electoral pero, una vez elegidos, continúan centrando su actividad política en el ámbito nacional, abandonando el europeo» (TORRES DEL MORAL, Antonio y VIDAL PRADO, Carlos, «Democracia representativa», en Comentarios a la Constitución Europea, Libro II, E. Álvarez Conde y V. Garrido Mayol (dirs.), Tirant lo Blanch, Valencia, 2004, p. 1405). La polémica cuestión de acumulación de actas nacionales y europea ha quedado zanjada por la Decisión del Consejo 2002/772/EC que prohíbe el doble mandato (artículo 7). Sobre las relaciones entre los partidos parlamentarios nacionales y los europarlamentarios a las que califica de «rivalidad institucional vertical», véanse las reflexiones de LODGET, Juliet, «Legitimidad democrática y Parlamento Europeo», Revista de Estudios Políticos, núm. 90, 1995, pp. 230-232. 


\section{REFLEXIONES FINALES}

La presencia de los grupos parlamentarios en el seno de los Parlamentos y, con ellos, la irrupción de los partidos políticos en el escenario institucional es incesante y polifacética puesto que se orienta en el plano orgánico (Mesa de la Cámara y de las Comisiones, Junta de Portavoces, Pleno, Comisiones y Ponencias, Diputación Permanente); funcional (iniciativa legislativa, procedimiento legislativo, control político, relaciones con otros órganos constitucionales o con las Comunidades Autónomas); procedimental (debates, votaciones, actas, publicaciones de las Cámaras, órdenes del día) e incluso en el ejercicio de funciones de carácter extraordinario (los portavoces de los grupos participan en reuniones con dirigentes extranjeros, representantes de grupos de presión o de interés, organizaciones sociales, partidos de origen, otras instituciones del Estado, organizaciones supranacionales,...). Como consecuencia de este protagonismo, la actividad del parlamentario ha quedado mediatizada por las entidades mencionadas y su posición queda definida por la subordinación de los criterios individuales al criterio general del partido a través de la disciplina de grupo y en la que las normas internas del grupo parlamentario exigen la dimisión y puesta a disposición del partido del acta de parlamentario en el supuesto de abandono del mismo o incluso mediante la existencia de renuncias firmadas en blanco y sin fecha extendiéndose hasta abarcar el aspecto económico mediante la participación de los grupos en las asignaciones económicas de sus miembros.

Las complejas relaciones entre parlamentarios, grupos y partidos que quedan al margen de las normas parlamentarias son plenamente asumidas en el plano sociopolítico e infraconstitucional pero plantean un claro contraste con la atribución personal del escaño al parlamentario y con la prohibición del mandato imperativo consagradas constitucionalmente (artículos 23.2 y 67.2 CE). La jurisprudencia constitucional ha sancionado sistemáticamente la consideración de que es el diputado, en sentido estrictamente jurídico, el que posee la condición de representante del pueblo y, por tanto, la irrelevancia jurídica de las sanciones impuestas desde los grupos y/o los partidos por incumplimiento de sus directrices.

El Tribunal Constitucional, al optar por fundamentar la independencia del parlamentario frente a los aparatos partidarios a través de la técnica de los derechos fundamentales, ha atribuido a los representantes la posición de titulares de una función a la que no pueden poner término decisiones ajenas a su voluntad y ha puesto a su disposición la titularidad del escaño como garantía última de su situación jurídica. Ciertamente, la contradicción entre la regulación constitucional que reclama la independencia de los parlamentarios y la re- 
alidad de su sometimiento a un verdadero mandato de partido engendra tensiones que no pueden, no obstante, solaparse con el cierto carácter voluntario de la disciplina que define el funcionamiento del grupo parlamentario. Voluntariedad que implica la observancia de la normativa interna de grupos y partidos en la que se contienen, fundamentalmente, medidas limitativas del status del parlamentario.

Por otra parte, a lo largo de las páginas precedentes, hemos destacado cómo la tendencia legislativa, reglamentaria e, incluso, jurisprudencial apunta en la dirección de profundizar en la inserción de los partidos políticos en el entramado institucional mediante cierta juridificación de la relación que existe entre los grupos parlamentarios y los partidos políticos.

Sostenemos que resulta posible hacer una lectura conciliadora de lo dispuesto en la Constitución española y la realidad parlamentaria reforzada en multitud de normas infraconstitucionales. Así, cabe entender que la representación política no se agota en los partidos - aunque sean el instrumento fundamental, como dice el artículo $6 \mathrm{CE}$ - sino que es preciso destacar también la función de los concretos representantes y la responsabilidad personal de los titulares del cargo $^{58}$ siendo posible dar un giro a la sobredimensión que han adquirido los grupos en las funciones parlamentarias volviendo a la figura del representante $\mathrm{y}$, en defensa de su posición, aprovechar todas las potencialidades individuales manteniendo, en todo caso, la protección constitucional como derecho fundamental y la garantía que eso conlleva frente a la voracidad de los partidos políticos.

Finalmente, el panorama descrito presenta un perfil distinto cuando nos aproximamos al nivel europeo puesto que, en la Eurocámara, todas las relaciones analizadas se ven influidas por el denominado doble vínculo que mantienen los parlamentarios con el partido nacional que lo incluyó en sus listas y, a su vez, con el grupo político europeo al que se adscribe una vez elegido. Esta multiplicidad de mandatos «debilita» el mandato del grupo sobre el diputado en el seno del Parlamento Europeo. No obstante, su reconocimiento se produce en los Reglamentos internos de los grupos políticos europeos que someten a sus miembros a las directrices emanadas de la entidad colectiva en abierta contradicción, nuevamente, con lo dispuesto en el derecho originario y parlamentario.

58 BOBBIO, Norberto, «Rappresentanza e interesi» en Rappresentanza e democrazia, G. Pasquino (ed.), Saggi Tascabili, Bari, 1988. 
Title

THE STATUS OF MEMBERS OF PARLIAMENT IN A MULTILEVEL CONTEXT: RELATIONS BETWEEN MEMBERS OF PARLIAMENT, GROUPS AND PARTIES.

\section{Summary}

1. INTRODUCTION: THE CONSTITUTIONAL POSITION OF PARLIAMENTARIANS WITH RESPECT TO THE BREAKDOWN OF THE REPRESENTATIVE MANDATE THEORY. 2. RELATIONS BETWEEN PARLIAMENTARY GROUPS AND POLITICAL PARTIES. REGULATORY FRAMEWORK. A) State and autonomous community regulation of relationships between groups and parties: the Constitution, Statutes of Autonomy and Parliamentary regulations. B) Internal party and group regulations: party statutes and internal group regulations. a) The party's political ideas and how they are received by the group. b) The symbiosis between party and group leaderships. 3. RELATIONS BETWEEN PARLIAMENTARY GROUPS AND THEIR MEMBERS. A) The position of the parliamentarian in the group. B) Voting discipline. 4. PARTIES, GROUPS AND MEMBERS OF THE EUROPEAN PARLIAMENT: PLURALITY OF MANDATES. 5. FINAL REFLECTIONS.

\section{Resumen}

El objeto del presente estudio consiste en analizar la posición del parlamentario desde la perspectiva de las relaciones que entablan los partidos políticos, los grupos parlamentarios y los representantes individualmente considerados en el Parlamento actual. Nuestro análisis reflexiona acerca de cómo las novedades legislativas, las últimas reformas operadas en los Reglamentos parlamentarios y los más recientes pronunciamientos jurisprudenciales profundizan en la dependencia entre aquellos tres elementos. El estudio del marco normativo estatal y del ámbito reglamentario en el que se desenvuelven esas relaciones; el examen de las relaciones que mantienen los grupos parlamentarios con sus miembros - especialmente, a través de medidas como la disciplina de grupo y sus consecuencias sobre el irresuelto problema de la prohibición de mandato imperativo y de la titularidad del escaño- o el análisis específico de estas mismas conexiones entre partidos, grupos y parlamentarios en el contexto del Parlamento Europeo constituyen los ejes centrales de nuestra reflexión. 


\begin{abstract}
The purpose of this study is to analyse the position of parliamentarians from the perspective of the relations established by political parties, parliamentary groups and representatives considered individually in the modern Parliament. Our analysis reflects on how new legislation, the latest reforms of Parliamentary regulations and the most recent case-law decisions have a far-reaching effect on the dependency between these three elements. The study of the State regulatory framework and the regulatory sphere in which these relations are developed; the examination of the relations parliamentary groups maintain with their members - particularly through measures like group discipline and its consequences for the unresolved problem of prohibition by imperative mandate and seat ownership - and the specific analysis of these same connections between parties, groups and parliamentarians in the context of the European Parliament form the central cores of our reflection.
\end{abstract}

Palabras clave

Partidos políticos, grupos parlamentarios, parlamentarios, mandato de partido y mandato representativo, Estado de partidos.

\title{
Key words
}

Political parties, parliamentary groups, parliamentarians, statute, party mandate and representative mandate, party state. 